\title{
Group 2 Innate Lymphoid Cells in Pulmonary Immunity and Tissue Homeostasis
}

\author{
Barbara C. Mindt ${ }^{1,2,3}$, Jörg H. Fritz ${ }^{1,2,3,4 * t}$ and Claudia U. Duerr ${ }^{1,2,3,5 * t}$ \\ ${ }^{1}$ Department of Microbiology and Immunology, McGill University, Montreal, QC, Canada, ${ }^{2}$ McGill University Research \\ Centre on Complex Traits (MRCCT), McGill University, Montreal, QC, Canada, ${ }^{3}$ FOCiS Centre of Excellence in Translational \\ Immunology (CETI), McGill University, Montreal, QC, Canada, ${ }^{4}$ Department of Physiology, McGill University, Montreal, QC, \\ Canada, ${ }^{5}$ Institute of Microbiology and Infection Immunology, Charité - University Medical Centre Berlin, Berlin, Germany
}

\section{OPEN ACCESS}

Edited by:

Chiara Romagnani,

Deutsches Rheuma-

Forschungszentrum (DRFZ),

Germany

Reviewed by:

Christoph Siegfried Niki Klose,

Weill Cornell Medicine, Cornell

University, United States

Rachel Golub,

Paris Diderot University,

France

*Correspondence:

Jörg H. Fritz

jorg.fritz@mcgill.ca;

Claudia U. Duerr

claudia.duerr@charite.de

tThese authors have contributed equally to this work.

Specialty section: This article was submitted to NK and Innate Lymphoid Cell Biology, a section of the journal Frontiers in Immunology

Received: 19 December 2017 Accepted: 05 April 2018 Published: 30 April 2018

Citation:

Mindt BC, Fritz JH and Duerr CU (2018) Group 2 Innate Lymphoid

Cells in Pulmonary Immunity and Tissue Homeostasis.

Front. Immunol. 9:840. doi: 10.3389/fimmu.2018.00840
Group 2 innate lymphoid cells (ILC2) represent an evolutionary rather old but only recently identified member of the family of innate lymphoid cells and have received much attention since their detailed description in 2010. They can orchestrate innate as well as adaptive immune responses as they interact with and influence several immune and non-immune cell populations. Moreover, ILC2 are able to rapidly secrete large amounts of type 2 cytokines that can contribute to protective but also detrimental host immune responses depending on timing, location, and physiological context. Interestingly, ILC2, despite their scarcity, are the dominant innate lymphoid cell population in the lung, indicating a key role as first responders and amplifiers upon immune challenge at this site. In addition, the recently described tissue residency of ILC2 further underlines the importance of their respective microenvironment. In this review, we provide an overview of lung physiology including a description of the most prominent pulmonary resident cells together with a review of known and potential ILC2 interactions within this unique environment. We will further outline recent observations regarding pulmonary ILC2 during immune challenge including respiratory infections and discuss different models and approaches to study ILC2 biology in the lung.

Keywords: group 2 innate lymphoid cells, respiratory tract, innate immune responses, lung physiology, pulmonary microenvironment

\section{INTRODUCTION}

Group 2 innate lymphoid cells (ILC2) have been identified less than a decade ago and constitute a new member of the family of innate lymphoid cells (1-3). From an evolutionary aspect, ILC2 are thought to be a rather old cell type with ancestor populations proposed in lamprey and bony fish (4). The indication of an innate lymphoid cell population linked to a type 2 immune response was first made in the 2000s: in mice, an IL-25-inducible non-T non-B cell population was reported to release large amounts of IL-5 and IL-13 (5), and in humans, a CD34+ population expressing both, IL-33R and TSLPR, was identified and shown to secrete type 2 signature cytokines upon stimulation with IL-33 or in combination with TSLP (6). In 2010, ILC2 were eventually described in detail and were discovered to reside in distinct tissues in mice and termed nuocytes, natural helper cells, or innate helper cells $(3,7,8)$. Despite the identification of ILC2 in various anatomical sites such as adipose tissue, liver, mesenteric lymph nodes (LNs), and the small intestinal lamina propria, 
common characteristics of ILC2 became apparent from these early studies. Those include their cytokine receptor expression profile, signature cytokines that are released, as well as their characteristic transcription factors. Thus, nomenclature of ILC2 was unified rather soon after their discovery (9). Until now, ILC2 have been described in mice and humans at varying body sites but with many overlapping characteristics: ILC2 share the ability to produce large amounts of type 2 cytokines within a short period of time and have common basic phenotypic characteristics regarding maintenance, regulation of surface molecule (e.g., CD127 and CD25) and transcription factor (e.g. GATA3) expression (9). However, it was also observed quickly that some variations in their typical phenotypic profile exist depending on the anatomical site and/or maturation level (e.g., expression of c-kit) (10). The location of ILC2 is not limited to mucosal sites, but due to their innate character and fast and immediate action, ILC2 are thought to be especially important at barrier surfaces. For example, in pulmonary immunity, ILC2 play a non-redundant role and are able to trigger airway hyper-reactivity even in the absence of adaptive immunity (7). However, it is clear that ILC2 are not isolated in their action and that their function and physiological role is regulated by and regulates other pulmonary hematopoietic and non-hematopoietic cells. In contrast to T helper 2 (Th2) cells, their adaptive counterparts, current evidence supports the notion that ILC2 are tissue resident and thereby act as key players within their corresponding tissue microenvironment $(11,12)$. Although all ILC types can be found at the mucosal surface of the small intestine, ILC2 are the predominant ILC population in the lungs at steady state. The reason for this skewed distribution of ILC populations in the lungs is not yet fully understood. However, the lungs provide without a doubt a unique microenvironment for ILC2.

In this review, we therefore focus on the pulmonary microenvironment, its physiology regulated by non-hematopoietic resident cells, and how ILC2 functionality is embedded within. We will further discuss different pulmonary infection and cytokine challenge models in which ILC2 effector functions have been shown to play important roles. We will only briefly address plasticity of ILC2 and their regulation since both have been recently discussed in an excellent review (13).

\section{LUNG PHYSIOLOGY AND THE PULMONARY MICROENVIRONMENT OF ILC2}

Group 2 innate lymphoid cells have been isolated from and were described in various tissues of the respiratory system. These reports include ILC2 from both mouse and human lungs (3, 7, 14-16) and adjacent sites such as human nasal and tonsil tissues (17). We will therefore give a short overview of our respiratory system and the main populations of tissue-resident cell populations focusing mainly on non-hematopoietic cells (Figure 1).

Our respiratory system can be divided into the upper and lower airways. The upper airways span from the nose (nasal cavity/ nasopharynx) to the pharynx (oropharynx and laryngopharynx) and further down to the trachea and bronchi. The bronchi branch into the smaller terminal and subsequently into the respiratory bronchioles from which the alveolar ducts are generated and end in the alveolar sacs consisting of several alveoli. The alveolar ducts and the alveoli compose the lower airways. The main responsibility of the respiratory system including these different parts is to ensure efficient gas exchange and thereby provide oxygen to the organism in exchange for carbon dioxide. To accomplish this, air is inhaled at a rate of several liters each minute in the resting state and delivered to this network of branching tubes. The blindended alveoli are the place of efficient exchange of carbon dioxide to oxygen. All other parts of the airways can be envisioned in an oversimplified way as a conduit, which serves for the airflow to reach the alveoli. However, the delivery of inhaled air through this conduit, which may be loaded with potential antigens, allergens, and pathogens, is controlled by mechanical filters, physiological barriers, active expel, and immune defense mechanisms (18). These tasks are accomplished by the interaction and interplay of approximately 40 distinct cell populations in the lungs (19). The well-organized and delicate structure of our respiratory immune system and its immediate surrounding is therefore a unique microenvironment for ILC2.

\section{The Upper or Conducting Airways}

The upper airways span from the nose and trachea to the bronchi (primary, secondary, and tertiary) and further down to the bronchioles (terminal and respiratory). The lungs start at the first branching point of the bronchi from the trachea. The character of the tissue of the bronchi still resembles the trachea with a pseudostratified, ciliated columnar epithelium including goblet cells, mucus glands, and cartilage. The cells of the epithelial layer are tightly interlinked via adhesion junctions composed of tight junctions, adherens junctions, and desmosomes, thereby establishing a firm physical barrier $(20,21)$. Throughout the branching of the tubular network, the epithelium changes its composition from the characteristic ciliated columnar epithelium in the trachea and larger bronchi to a mix of non-ciliated and ciliated cells in the bronchioles and terminal bronchioles to the respiratory bronchioles with rare occurrence of ciliated cells (18). Several different epithelial and non-epithelial lung resident cells will be discussed below.

\section{Goblet Cells}

Goblet cells are defined by their goblet or cup-like shape that is acquired by their inner cellular structure of secretory granulae filled with mucins (22). Goblet cells are present in humans in the trachea and bronchi as well as in the submucosal glands at steady state and absent in the smaller branching of the airways. However, they can be induced upon infection or challenge. In the non-challenged laboratory mouse, goblet cells are mainly restricted to submucosal glands but can be induced upon challenge in trachea, larger bronchi, and even in the bronchioles. The distribution of goblet cells is an important difference between mouse and human physiology (23). IL-13 is key for goblet cell hyperplasia and function such as mucus secretion $(24,25)$ and is also one of the signature cytokines that is produced and released by ILC2 (26). 


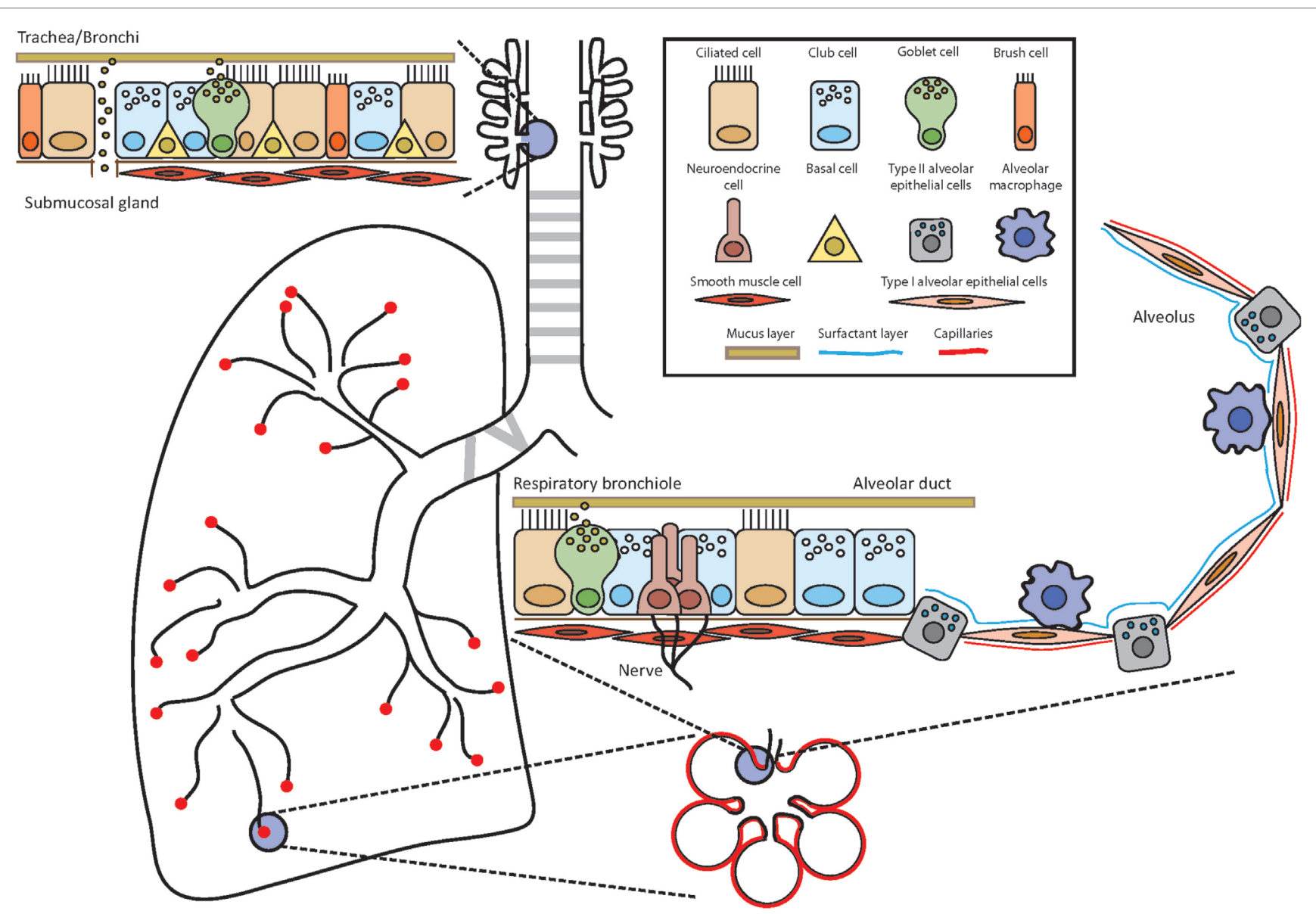

FIGURE 1 | Anatomy of the airways. Throughout the airways, the cell composition of the epithelium changes to ensure optimal and efficient gas exchange as well as maintenance of lung integrity and defense against potential pathogens and allergens. Depending on the location, the epithelium is composed of several different cell types such as ciliated cells, club cells, brush cells, goblet cells, airway smooth muscle cells, neuroendocrine cells, type I and type II alveolar epithelial cells, and alveolar macrophages. Basal cells have the potential to differentiate into several lineages and serve as stem cells.

\section{Club Cells}

Club cells or bronchiolar exocrine cells have characteristic short microvilli, a dome shape, and are present in bronchioles (terminal to respiratory). Club cells secrete surfactant proteins (surfactant protein A, B, and D) and express Clara cell $10 \mathrm{kDa}$ protein (CC10, Scgb1a1), which can bind to surfactant lipids. Club cells are able to self-renew but also to differentiate into ciliated cells to regenerate the epithelium (27) as well as into goblet cells (28).

\section{Pulmonary Neuroendocrine Cells (PNECs)}

Pulmonary neuroendocrine cells are a rare cell population, which represent only approximately $1 \%$ of the airway epithelium. PNECs are present in clusters, termed neuroepithelial bodies, and are located at airway branching points. They are an innervated epithelial cell population (29), sense changes in oxygen levels, and release neuropeptides (calcitonin gene-related peptide), neurotransmitters (serotonin), and bombesin-related peptide (Neuromedin B) (30). In addition, PNECs play a role in the modulation of smooth muscle tonus. Since PNECs transmit environmental signals via the rich network of neural fibers (postganglionic parasympathetic neurons and the vagus nerve) to the central nervous system, they serve as a link between the nervous and endocrine system. A role of PNECs in immune responses and tissue remodeling has been recently reported (31) and deregulated PNECs are associated with different respiratory diseases such as chronic obstructive pulmonary disease (COPD) (32) or asthma (33).

\section{Brush (Microvillous) Cells}

The role of brush cells (Tuft cells, caveolated, multivesicular, and fibrilovesicular cells) in normal airways and alveoli is poorly understood yet, albeit their existence has been known for some time (19). Brush cells are pear or flask-like shaped cells (wide base and narrow microvillous apex) with a tuft of blant and broad, squat microvilli. They have first been described in the airway epithelium and later in alveoli (alveolar lining) as the third pneumocyte in addition to type I and type II airway epithelial cells (34). In humans, brush cells exist from the nose to the alveoli, but are only present in alveoli in disease states (35). In the mouse, brush cells are abundant in the trachea (36). Interestingly, brush cells express (bitter) taste receptors and are able to regulate breathing by signal transmission to neurons of the vagus nerve $(36,37)$. Brush cells 
are not only present in the mucosa of the respiratory tract but also in the small intestine. Here, brush cells are termed tuft cells and have recently been shown to constitute an important source of the ILC2-stimulating cytokine IL-25 (38-40). Furthermore, IL-13 secreted by ILC2 is able to induce tuft cell hyperplasia in the small intestine, indicating a positive feed forward loop (38-40). However, although IL-25 can be detected in pulmonary tuft cells as well, it is currently unknown whether a similar regulatory interaction between tuft cells and ILC2 is also of functional relevance in the lungs. Upon intranasal administration, IL-25 is significantly less potent in eliciting a pulmonary type 2 immune response compared with IL-33 and also does not increase pulmonary ILC2 $(41,42)$. The mode of IL-25 administration (intranasal vs systemic) is also key in eliciting different ILC2 populations in the lung $(43,44)$ and as such it is not known yet if and to what extent brush cells are involved in induction of different pulmonary ILC2 subgroups.

\section{Nerve Cells (Neurons)}

Neurons have a very characteristic shape due to their function: their cell body is surrounded by dendrites to carry (electrical) impulses to the cell and a long axon is used to transfer impulses to other cells. Impulses are transmitted via the synapse, a gap between the axon of one neuron and the dendrites of another neuron. The upper and lower airways are innervated with neurons of nerves such as the vagus nerve (pneumogastric nerve, cranial nerve $\mathrm{X}$ ) emerging from the base of the brain to the chest and lungs, and then passing the heart to the colon. The vagus nerve belongs to the parasympathetic division of the (peripheral) autonomic nervous system, which controls involuntary processes such as the regulation of the heart and respiratory rate (via smooth muscle cells) as well as the orchestration of glands and mucous secretion (45). The axons of the vagus nerve's neurons branch off into all parts of the airways. Vagus nerve stimulation leads to constriction of the airways and is essential for actual breathing (46). Spinal nerves transmit impulses between the spinal cord and the body. Several different spinal nerves are present in the body amongst them are the twelve pairs of thoracic nerves, which emerge from the thoracic vertebrae and are further divided into proximal and distal branches. Clusters of neuron cell bodies (soma) make up a ganglion and can be identified as swellings along nerves. In addition, impulses for defense mechanisms are initiated such as coughing, which is often deregulated and/or dysfunctional in airway diseases $(47,48)$. The neuro-immune axis is increasingly becoming the central focus of current pulmonary research and a link between ILC2 function and neurons has been described just recently (see below).

\section{Airway Smooth Muscle Cells (ASM)}

Airway smooth muscle cells cover the complex branching network of the bronchial tree in a circumferential fashion and perpendicular to the axis of the tube (49). At the start of the trachea, ASM lie in an almost complete sheet of smooth muscle in the posterior wall of the trachea at the opening of the C-shaped cartilage. This almost complete ring of ASM breaks down in the main bronchi between the ends of the U-shaped cartilage rings. In the subsequent bronchi, ASM form discontinuous bands between outside extremities of each cartilage ring. These muscular walls with cartilage rings extend from the larynx over the primary bronchus to the smaller bronchi in humans. From the bronchioles onward, the smooth muscle fibers lie between adventitial tissue and epithelium and the cartilage decreases with the presence of these incomplete muscular walls. In mice, no cartilage plates are present in the lower airways, and ASM muscle bundles describe helical patterns from the medium bronchi to the alveolar duct. Thereby, ASM build an important support structure for the lungs and prevent its collapse. Moreover, ASM are key for the contraction of the airways. But ASM may also play an important immunological role in the lungs with the expression of immune mediators and cytokines or their expression of (bitter) taste receptors (50). The implication of ASM in asthma has been reported almost a century ago since ASM mass is increased in asthma patients (51). However, the exact contribution and function of ASM in respiratory diseases, their cytokine secretion, induction of proliferation, as well as their potential interaction or competition with other pulmonary cell populations still needs to be elucidated in detail.

\section{Stem Cells}

The lungs show a low regenerative rate at steady state in contrast to other mucosal tissues such as the small intestine. However, upon infection or challenge, the lungs are able to initiate a high-regenerative turnover program (52). Basal cells have been described as the putative stem cells, are shared between bronchioles and alveoli, and have been suggested to generate ciliated, mucous, and neuroendocrine cells (23). In 2005, these basal cells were termed bronchioalveolar stem cells and their importance for lung regeneration but also for cancer was described (53). Recently, two reports identified two slightly different stem cell populations in mice upon influenza virus infection $(54,55)$. These stem cells have epithelial characteristics with the formation of Krt $-5^{+}$cell clusters (pods) as an important and characteristic feature. Interestingly, these cells are able to migrate from a distal position to the injured tissue area, where they serve as progenitors for different cellular lineages such as type I and type II pneumocytes $(54,55)$. However, repair mechanisms in human lungs are far less understood than in mice.

\section{Submucosal Glands}

Mucus glands are present in the lamina propria of the trachea and bronchi but absent in the distal tubular network (18). Their lamina propria is a loose and collagen rich structure, which supports the pseudostratified columnar epithelium of the trachea and bronchi.

\section{Lower or Respiratory Airways}

The alveoli of the lower airways are the place where oxygen is drawn and carbon dioxide is discarded. Whereas no cartilage is present in the alveolar duct and alveoli, smooth muscle cells are quite rare in the alveolar duct and absent in the alveoli. The delicate organization of the alveoli provides the perfect physiological anatomy to ensure this exchange. The alveoli are lined by type I and type II alveolar epithelial cells (pneumocytes). Type I cells are flat and spread out and thereby cover approximately $90 \%$ of the alveolus' surface area even if they are not the most 
frequent cell population in numbers. Thereby, they provide a thin cellular layer, which serves as an optimal respiratory surface. Importantly, type I cells are not able to divide but can be restored by type II cells differentiating into type I cells (56). Type II cells are of cuboid shape and have characteristic microvilli on their apical surface and lipid rich lamellar bodies containing surfactant proteins. Surfactant proteins cover the alveolus surface in a thin layer and are important to prevent a collapse of the alveoli during breathing but also exert antimicrobial activity (57). Type II cells also produce cytokines such as TNF $\alpha$ (58). Alveolar macrophages are situated in close proximity to type I or type II cells lining the alveolus as well as in the alveolar space. Moreover, type I cells are in close contact to the endothelial cells of the alveolar capillary which are key for gas exchange. The alveolar capillaries are circumventing alveoli with a network so that every capillary is lining two alveoli, one from each side, thereby an optimal gas exchange is guaranteed. The alveolar capillaries are present within the septae, which separate the alveoli from each other. Interestingly, each alveolus is not isolated but connected to adjacent alveoli by discrete holes, termed the pores of Kohn or interalveolar connections (59). These alveolar pores have been proposed to play a role in ensuring that the lungs do not collapse and equalize pressure. They are important in collateral ventilation and ensure minimal ventilation even if the lung partially deflates. However, other observations suggest that these pores are not empty (60), which could indicate that these interalveolar connections allow spreading of small particles and other infectious material such as bacteria or viruses. Moreover, it has been suggested that immune cells such as alveolar macrophages are able to migrate through these pores (61). It is tempting to speculate that upon challenge pulmonary ILC2 might use these pores as a passageway to get from one alveolus to another and thereby survey the tissue.

The organization of human and mouse lungs is very similar in general; however, several important differences exist, and some of them have been already mentioned in this review. For the sake of completeness, we would like to point out that unlike in humans, the mouse lung consists of five lobes: the left lung, and the right lung with the superior, middle, inferior, and post-caval lobes. By contrast, the human lung is composed of the two lobes (upper and lower lobe) of the left lung, and three lobes of the right lung (upper, middle, and lower). In addition, the branching pattern of the airways is less complex in mice compared to humans $(62,63)$, with the predominant cell types of the conducting airways being ciliated cells in humans, whereas more secretory cells are present in mice $(64,65)$.

\section{DEFINITION AND CHARACTERISTICS OF PULMONARY ILC2}

The definition of pulmonary ILC2 was shaped by their first identification in cytokine reporter mice. Here, pulmonary ILC2 were defined by their respective reporter signal in IL-4 (4get) and IL-13 (YetCre-13) reporter animals (3). Later on, ILC2 were described in the lungs of non-reporter and wild-type mice. Although the gating strategies vary, ILC2 are in general defined as lineage negative cells, which are positive for Thy1, Sca-1,
GATA-3, T1/ST2, inducible T cell costimulator (ICOS), CD44, CD25, CD127, KLRG1, and c-kit low to positive (7, 14, 66-68). These characteristics of pulmonary ILC2 also are consistent with ILC2 at other mucosal sites such as the gut $(2,67,69)$. To the best of our knowledge, there is so far no sole known (surface) marker or characteristic that defines ILC2 at one site but is not present or inducible at any other site. This is supported by the current concept that ILC2 represent one group of innate lymphoid cells, but that this group is not always homogenous. Single-cell sequencing analysis of ILC2 cells at steady state in the small intestine showed that ILC2 are indeed heterogeneous and several subgroups with different gene expression patterns were identified (70). Moreover, an approach using signature type 2 cytokine reporter mice revealed that pulmonary ILC2 exhibit different mRNA expression patterns of these cytokines when compared with small intestinal ILC2. Il5 is expressed at steady state in both pulmonary and intestinal ILC2, whereas Il13 is continuously expressed in small intestinal ILC2, but can be induced in pulmonary ILC2 upon challenge (71). In the lungs, inflammatory (i) and natural ILC2 (nILC) have been reported upon systemic administration of IL-25 or IL-33. Although these ILC2 subgroups are well defined by their slightly different surface markers, namely high killer cell lectin-like receptor subfamily $\mathrm{G}$ member 1 (KLRG1) expression for iILC2 and ST2 expression for nILC2, a transition has been noted between iILC2 and nILC2, highlighting a strong relation of these two populations (43). These reports underline that ILC2 belong to one group within the ILC family but that ILC2 biology and characteristics are highly influenced and shaped by their respective microenvironment, its immunological profile at steady state as well as upon immune challenge.

Our knowledge of human pulmonary ILC2 is limited at the moment due to the fact that the accessibility of human lung samples is highly restricted. The information about human ILC2 originates from deceased patient material (organ donors) or from surgeries of the lungs such as routine bronchoscopy upon lung transplantation. In those tissues, ILC2 can be detected and defined as lineage negative, $\mathrm{CD} 127^{+} \mathrm{CD} 25^{+}$and $\mathrm{ST} 2^{+}(14)$ and thereby share important characteristics with mouse ILC2. In lungs of idiopathic pulmonary fibrosis and COPD patients, ILC2 were identified as lineage negative, $\mathrm{CD} 127^{+} \mathrm{ST} 2^{+} \mathrm{ILC} 2$, or lineage negative, $\mathrm{CD}_{127^{+}} \mathrm{CRTH}_{2}^{+}$ILC2. ST2 ${ }^{+}$ILC2 show high expression of arginase 1 , which was identified in this elegant study as an important characteristic for ILC2 functionality (15). Human ILC2 obtained from patients undergoing lung tumor surgery can be identified as $\mathrm{CD} 45^{+}$and $\mathrm{CD} 127^{+}$cells upon excluding lineage positive cells. Interestingly, compared with ILC2 from nasal polyps of chronic rhinosinusitis patients, these pulmonary ILC2 exhibit differences in their pattern of CRTH2 (chemoattractant receptor-homologous molecule expressed on Th2 cells) and c-kit expression (16), which might be due to their distinct microenvironment. Furthermore, CRTH2 was recently identified to play a role in ILC2 accumulation in the lungs of human and mice, and differences in CRTH2 expression between human peripheral blood (high) and pulmonary (low) ILC2 (lineage $\mathrm{CD} 127^{+} \mathrm{CD} 45^{+} \mathrm{ST} 2^{+}$) may as such determine tissue localization and function (72). These data underline that human and mouse ILC2 share biologically important similarities. 


\section{TISSUE RESIDENCY AND LOCAL DISTRIBUTION OF PULMONARY ILC2}

In the lungs, the presence of hematopoietic cells at steady state is relatively low compared with other mucosal sites such as the small intestine. However, $\mathrm{B}$ and $\mathrm{T}$ cells [including $\mathrm{T}$ regulatory (Treg) cells], alveolar and interstitial macrophages, different types of dendritic cells, and ILC can be detected in addition to resident, non-hematopoietic cells (described above). Interestingly, ILC2 are the predominant ILC population in the lungs at steady state (14). Although the localization and migration capacity of ILC2 determine their (potential) interaction partners, we are only just beginning to understand these dynamics.

Based on observations made by two recent studies using a parabiosis approach, ILC2 are regarded as tissue-resident cells. No significant numbers of ILC2 of the parabiont host were found in the lungs within 4 months of parabiosis (11). Strikingly, even within one week post Nippostrongylus brasiliensis infection, only host ILC2 were detected in the lungs, underlining the tissue residency of ILC2. However, two weeks post-infection a significant increase of donor-derived ILC2 were detected in lung, small intestine, and $\mathrm{mLN}$, while no changes were observed for ILC3 in the small intestine. This might reflect the limited local proliferation of the small and insignificant number of donor ILC2 during the infection. In another elegant study, Koyasu and colleagues analyzed parabiotic pairs after more than one month of shared circulation for pulmonary $\mathrm{T}$ cells, ILC2, and eosinophils at steady state, or up to one week post intratracheal IL-33 challenge. Whereas $\mathrm{T}$ cells and eosinophils are present from donor and host in this parabiotic pair, ILC2 of the parabiotic donor could not be detected (12), underlining that ILC2 remain local and do not migrate into the parabiotic host. Both reports elegantly show and strengthen the current notion that ILC2 are tissue-resident cells that primarily retain their tissue residency at steady state as well as during immune challenge. Interestingly, ILC2 have been shown to accumulate in the mouse lungs during ontogeny with ILC2 numbers peaking at about two weeks after birth (73, 74). The ILC2 of these immature mice exhibit increased levels of intracellular cytokines when compared with ILC2 in adult animals and are to some extent dependent on IL-33. Upon challenge with house dust mite (HDM), more IL-33 protein can be detected in lungs of immature mice compared to adult mice accelerating innate as well as adaptive type 2 immune responses $(73,74)$. However, further research will be needed to better understand how ILC2 are directed to find their respective tissue niches during ontogeny. Moreover, since ILC2 are observed in lungs at steady state and upon challenge, the question remains where within the tissue these cells are exactly located, how they take part in tissue surveillance and which cellular interactions with other resident and infiltrating cells are established, supported, and needed for maintenance and function in acute and chronic lung diseases.

In addition, it will be of great interest to understand how and under which circumstances ILC2 egress from the bone marrow as well as how they migrate between distinct peripheral tissues. A recent study by Stier and colleagues sheds light on the migratory ability of ILC2. They observed that IL-33 is key in regulating ILC2 egress from the bone marrow (75) since ILC2P in IL-33-deficient mice show similar fitness to wild-type mice but are retained in the bone marrow due to higher expression of CXCR4. In addition, by using an elegant combination of parabiosis and tissue injury, they show that ILC2 are capable of migration after sublethal irradiation and thereby repopulating the empty ILC2 niche. This report demonstrates that under specific circumstances ILC2 are indeed able to traffic, even if mainly regarded as a tissue-resident population. In this report, ILC2 are identified by their expression of the IL-25 receptor chain (IL-25R or IL-17RB), which identifies ILC2 progenitors in the bone marrow (76) but limits detection to ilLC2 (43) as well as memory ILC2 (77) in peripheral tissue. If this holds true for ILC2 in general including nILC2, which are in contrast identified based on lower levels of KLRG1 and alternatively by GATA3 expression, still needs to be elucidated. Another elegant report using parabiotic mice identifies that iILC2 are able to migrate from the small intestine to the lungs upon systemic (i.p.) IL-25 administration or helminth infection (78). This study further shows that especially intestinal iILC2 have the potential to migrate and that this migration is regulated in a S1Pdependent manner. Interestingly, upon systemic IL-25 challenge, nILC2 reside in the alveolar space in contrast to iILC2, which are confined to the vascular space.

In addition, S1PR1 (S1pr1) and L-selectin (CD62L, Sell) expression was detected in naïve lung ILC2 and decreased upon stimulation with IL-33 (77). The adaptive counterpart of ILC2, T cells are guided by S1PR1, which binds to S1P1, to exit secondary lymphoid organs and the thymus (79). Moreover, ILC2 have been detected in the mesenteric LN upon systemic challenge (2) but also in the mediastinal LN of the lungs upon intranasal administration of IL-33 or papain (77). This might be due to proliferation of local tissue-resident ILC2 or active migration. However, the ability of homing of ILC2 from distal sites, such as the lung or small intestinal tissue, to the respective draining LNs is only beginning to be understood. In an elegant study using Kaede transgenic mice in which distinct cell movements can be tracked via a photoconvertible fluorescent protein, Mackley and colleagues show that all ILC populations constitutively traffic from the small intestine to the $\mathrm{mLN}$ (80). Interestingly, this migration is only dependent on the CCR7 receptor for LTilike ILC3, but not for ILC1 or ILC2 (80). Moreover, opposite trafficking from the mLN to the small intestine is dependent on CCR7 for ILC1 and ILC3 and their further migration to the small intestine is regulated by a retinoic acid regulated homing receptor switch in contrast to ILC2 (81), further indicating that different homing programs exist for the different ILC populations. Importantly, immunofluorescence analysis revealed that ILC2 and ILC3 are located in close proximity to each other, within the interfollicular space, in the mLN (80). Whereas both of these ILC populations as well as ILC1 are present in all investigated LNs, this close proximity of ILC3 and ILC2 was only observed in the mLN (80). Interestingly, ILC3 are most prominent in wild-type mice in the $\mathrm{mLN}$, but the ratio is shifted to higher levels of ILC2 in Rag-deficient mice (80). How this imbalance is caused has not been fully understood but a different activation and metabolic state in ILC3 in Rag1-deficient mice compared with wild-type mice has been recently reported (82) 
and this might in addition interfere with the trafficking ability of ILC3. However, whether communication between ILC2 and ILC3 in the special microenvironment of the mLN and in draining LNs exists and if this is a general phenomenon still needs to be determined.

Thus, ILC2 might support immune reactions not by circulating through the blood to reach peripheral tissues, but by traveling rather short distances to a respective LN. It is tempting to speculate that ILC2 might have a special function within the elicited immune response at a defined location similar to what has been described for natural killer (NK) cells (83). However, the importance of the microenvironment for ILC2 in the mediastinal $\mathrm{LN}$ and the regulatory mechanisms of homing to and from it as well as to the lungs still need to be elucidated.

In contrast to mice, ILC2 have been identified in the blood of humans since their detailed description (16). Lombardi et al. investigated patients with allergic rhinoconjunctivitis with or without asthma and healthy, non-allergic individuals (84). Surprisingly, the number of ILC2 as well as cytokine production profile is similar between healthy donors and allergic subjects. However, ILC2 are slightly increased in asthmatic patients compared with non-asthmatic within the group of allergic subjects. However, this trend is also observed with peripheral ILC3. mRNA sequencing comparing allergic and non-allergic subjects revealed an increase of genes involved in the activator protein 1 molecule and suggests a higher activity of its related pathway. Importantly, surface expression of the CCR10 receptor on ILC2 was significantly elevated in allergic compared with non-allergic individuals and expression of CCR10 can be correlated to increased severity of asthma. However, no change was observed in CCR4 expression in peripheral blood of allergic and non-allergic individuals (84).

Since ILC2 are the dominant population of ILC in the lungs, it is important to determine their location(s) to understand their biology, cellular interaction partners, as well as the influence of the pulmonary microenvironment on their function. The first report on the localization of pulmonary ILC2 identified them in collagen rich structures in close proximity to the airways at steady state by using an IL-5 reporter mouse (71). This location was further defined to be close to the epithelium and small conducting airways (8). Upon IL-33 challenge, pulmonary ILC2 are often situated in clusters that are located in the vicinity to the airway epithelium as well as in the alveolar space. The formation of these ILC2 clusters is not limited to cytokine administration and has been also detected in alveolar spaces of helminthinfected mice (N. brasiliensis, two weeks post-infection) (8). Interestingly, clusters of ILC2 are situated close to infected foci/cells of bronchioles and alveoli upon influenza infection (ST2-GFP-reporter mice) (85). Upon pneumectomy, ILC2 are induced and have been identified in the conducting airways and in the alveolar space using IL-5 reporter mice (86). Recent reports further identified that ILC2 are located in the vicinity of (enteric) neurons $(41,87)$.

In summary, ILC2 are located at peripheral and central sites of the lungs at steady state and are present in clusters within affected cellular foci upon challenge. The appearance of these ILC2 clusters is interesting and raises the question of whether
ILC2 actively proliferate at these locations due to stimuli provided by their infected microenvironment or/and if they migrate from more peripheral locations toward these infected foci. Moreover, it will be of interest to decipher whether pulmonary ILC2 are able to keep the lung tissue under surveillance similar to skin ILC2 (88), and thereby actively contribute to the homeostasis of the lungs. In addition, passing and migrating through the pores of Kohn would be a huge advantage to reach alveoli as speculated above and as was proposed for macrophages (61). However, how and if these migration activities of ILC2 are directed still remains elusive.

\section{PLASTICITY OF PULMONARY ILC2}

Group 2 innate lymphoid cells have been originally identified in different organs under different conditions and with slightly different characteristics. The key characteristics of ILC2, which have led to their standardized nomenclature were mainly the expression of the transcription factor GATA3, the expression of surface receptors such as ST2, and the production of type 2 signature cytokines. However, it has been observed that ILC2 are able to adapt due to different challenges and microenvironments. This plasticity of ILC2 changes the typical ILC2 characteristics such as transcription factor expression, cytokine expression, and surface receptor expression or a combination thereof. Upon IL-25 challenge, iILC2, which have migrated from the small intestine, are observed in the lungs $(43,78)$. iILC2 express both GATA3 and ROR $\gamma \mathrm{t}$ and have the potential to express IL-17 besides IL-13 in ex vivo culture experiments, thereby iILC2 can as well support antifungal immune responses. In addition, iILC2 exhibit plasticity by transitioning to nILC2 characterized by ST2 instead of IL-17RB surface expression under certain conditions (43).

Importantly, ILC2 downregulate the key transcription factor GATA3 upon respiratory challenges of viral or bacterial origin as well as environmental pollution such as cigarette smoke. These converted ILC2 are able to secrete IFN- $\gamma$ in response to IL-12 and IL-18 (85). Of note, human ILC2 are able to adapt to this ILC1-like phenotype when cultured with IL-12 (89). Moreover, the induction of this conversion in human ILC2 is initiated by IL- $1 \beta(89,90)$. Interestingly, IL- $1 \beta$ in combination with IL-2 is a strong activator of human peripheral blood ILC2 and signals through NF- $\mathrm{B}$ $(89,90)$. Thus, ILC2 plasticity is of high importance regarding the development of therapeutics to counter pulmonary type 2 immunopathologies.

\section{CELL SURFACE RECEPTOR-LIGAND INTERACTIONS OF ILC2 WITH OTHER CELLS OF THE PULMONARY ENVIRONMENT}

Group 2 innate lymphoid cells express various surface molecules that can interact with their respective ligands on other cells. However, only a small number of all possible cell-cell contacts of ILC2 with other lung populations have been studied so far, as depicted in Figure 2, and will be further discussed below. 


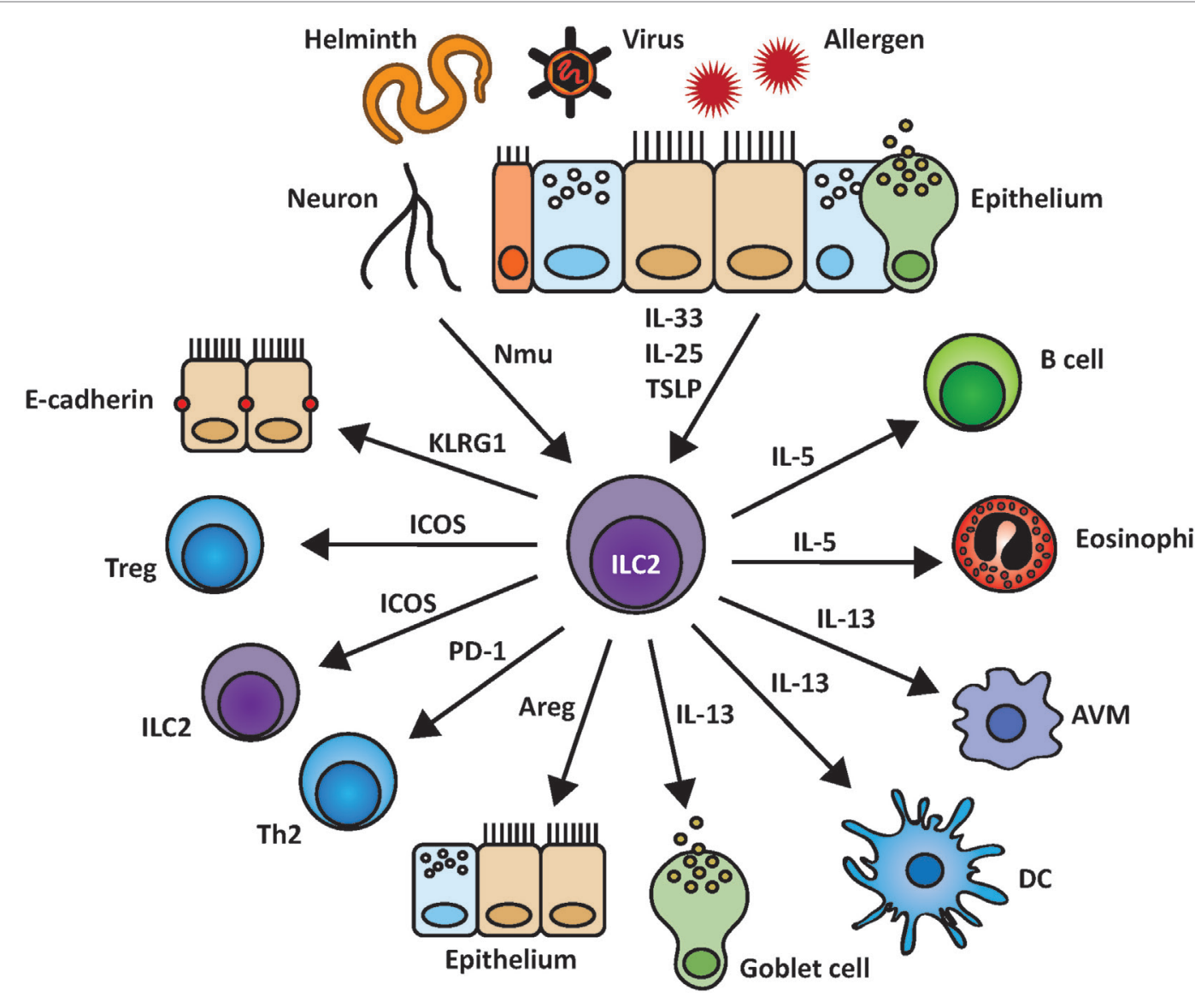

FIGURE 2 | Group 2 innate lymphoid cells (ILC2) and their interactions within the pulmonary environment. ILC2 are induced by epithelial-derived cytokines as well as by other biological mediators such as the neuropeptide neuromedin U (NMU). Upon activation, ILC2 are able to stimulate and communicate with other cell populations by indirect cytokine based or cell-cell mediated interactions including the release of IL-5, IL-13, and amphiregulin (Areg) and binding of KLRG1 to E-cadherin.

\section{ICOS-ICOS-L}

Inducible $\mathrm{T}$ cell costimulator (CD278) belongs to the CD28 family and is an important molecule in $\mathrm{T}$ cell signal transduction $(91,92)$. ICOS is expressed by mouse and human ILC2 independent of their location, at steady state but also upon stimulation. Deficiency of ICOS or its ligand ICOS-L leads to reduced numbers of ILC2 in the lungs (and small intestine) in combination with lower surface expression of KLRG1 (93). Moreover, ICOS and ICOS-L-deficient mice show reduced levels of pulmonary ILC2 upon intranasal IL-33 stimulation $(93,94)$. ICOS deficiency in ILC2 in the lungs has also been linked to reduced survival, cytokine production, and pSTAT5, all key for efficient function and signal transduction of ILC2 (94). In the lungs, both, Treg cells and ILC2 are rare at steady state, but can be located at similar sites (8). Interestingly, Tregs have been reported to suppress ILC2 function via ICOS and ICOS-L interaction. This interaction appears to take place independent of their location since it was observed in the lungs as well as in visceral adipose tissue (8). However, it is not yet known which signals direct the colocalization of Tregs and ILC2 in vivo. Another report investigated the potential of ILC2 suppression by Tregs via ICOS-ICOS-L interaction (95).
Interestingly, major differences of the suppressive potential of inducible Tregs (iTregs), and natural Tregs (nTregs) were observed. Only iTregs but not nTregs suppressed ILC2 and lead to reduced cytokine secretion by ILC2 (95).

\section{Programmed Death 1 PD-1-PD-L1/PD-L2}

Programmed death 1 (CD279) is another member of the CD28 family like ICOS and has been described as an important negative regulator of $\mathrm{T}$ cells (96). Recently, PD-1 treatment has been successfully used in cancer therapy (96). Both ligands for PD-1, PD-L1, and PD-L2, are expressed on various immune and non-immune cells (96). Importantly, ILC2 biology has recently been shown to also be influenced by PD-1 and its ligands. PD-1 is a key factor for ILC2 development and function and is expressed on mature ILC2 as well as on ILC2 progenitors $(76,97)$. PD-1 negatively regulates KLRG1 ${ }^{+}$ILC2 by inhibiting STAT5 phosphorylation, leading to reduced ILC2 proliferation and cytokine production (97). Deficiency in or blocking of PD-1 results in enhanced ILC2 effector function (97). PD-1 and PD-L1 are upregulated on ILC2 upon immune challenge including IL-33 stimulation (97) or N. brasiliensis 
infection (98). The latter study identified that ILC2 interact via $\mathrm{PD}-\mathrm{L} 1$ with $\mathrm{PD}-1$ on Th2 cells and promote their type 2 effector function (98). Thereby another important regulatory mechanism of ILC2 and their adaptive counterpart, the Th2 cells was identified. Moreover, the importance of the induction of PD-1 or PD-L1 on ILC2 by probably local cells is key to trigger type 2 immune responses.

\section{KLRG1-E-Cadherin}

Killer cell lectin-like receptor subfamily $\mathrm{G}$ member 1 is expressed on T cells and NK cells and binds to cadherins (E, N, and R). In contrast to $\mathrm{N}$ - and R-cadherins, which are expressed by the nervous system, E-cadherin can be found on epithelial cells as well as on Langerhans cells of the skin (99). A suppressive effect of the interaction of E-cadherin with KLRG1 on human skin ILC2 has been shown, resulting in reduced proliferation and cytokine expression as well as downregulation of GATA3 (100). Pulmonary KLRG1+ ILC2 may interact with E-cadherin expressed on lung epithelial cells, especially as part of the adherens junctions, which are located basolateral below the tight junctions and are part of the intercellular junctions formed by the lung epithelium $(62,101)$. Especially of interest is that high KLRG1 expression has been reported as a surface expression characteristic of iILC2 in the lungs (43). In humans, E-cadherin loss and presence in the sputum correlates with asthma severity (102). However, the exact mechanisms and the downstream signaling pathways within ILC2 upon KLRG1 ligation are not yet understood. Moreover, whether pulmonary ILC2 are able to interact with $\mathrm{N}$ - and R-cadherins expressed by the nervous system via KLRG1 still remains elusive.

\section{MHC Class II (MHC-II)-TCR}

Different populations of ILC, including ILC2, have been reported to express or upregulate MHC-II upon activation $(2,103,104)$. However, the role of MHC-II activation for ILC2 function was just recently deciphered $(105,106)$. ILC2 express MHC-II upon systemic IL-33 activation to a various extent depending on their location (106): pulmonary ILC2 show less MHC-II expression compared with small intestinal ILC2. ILC2 express functional MHC-II and are able to process and present antigen (106). However, MHC-II expression on ILC2 is only stable in vivo and ILC2 loose MHC-II cell surface expression when cultured ex vivo for longer periods of time (106). The reasons for that are not yet understood. However, the importance of MHC-II on ILC2 was shown to be independent of the expression levels of MHC-II (106). In addition to systemic administration, intranasal administration of IL-33 induces MHC-II expression on a subpopulation of pulmonary ILC2 (106). Interestingly, despite its heterogeneous expression of MHC-II, the resulting ILC2 population is able to present antigen to T cells. Moreover, IL-2 secreted by $\mathrm{T}$ cells further supports type 2 cytokine secretion and proliferation of ILC2 in co-culture experiments $(105,106)$. Thus, MHC-II on intestinal ILC2 is important to amplify type 2 immune responses in intestinal infections ( $N$. brasiliensis). Further research will elucidate whether this mechanism also comes into play for the regulation of beneficial and detrimental type 2 immune responses in the lungs.

\section{INDIRECT INTERACTIONS OF ILC2 WITH OTHER CELLS OF THE PULMONARY ENVIRONMENT}

In addition to direct cell surface receptor-ligand interactions of ILC2 with other non-hematopoietic and/or hematopoietic cells, ILC2 sense their microenvironment and can be regulated by certain cytokines including IL-25 and IL-33 and other immune mediators, which has been recently reviewed (107). However, expression, processing, and release of mediators regulating ILC2 and their cellular origin at steady state and upon immune challenge are poorly investigated and further research is needed to determine their detailed activation mechanism in the pulmonary environment (Figure 2). In addition, cells activating ILC2 are no longer limited to epithelial, endothelial or hematopoietic origin since neurons have been recently added as important regulators of ILC2.

\section{Regulation of ILC2 by Neurons Neuromedin U (NMU)}

Three recent reports demonstrated that the neuropeptide NMU is a potent activator of ILC2 in the intestinal and respiratory tract $(41,87,108)$. NMU is expressed by cholinergic neurons that use the neurotransmitter acetylcholine to transmit impulses. Cholinergic neurons are part of the enteric nervous system, the parasympathetic vagal nerve, and the thoracic dorsal root ganglia (described above). NMU signals via the receptors NMUR2, which is mainly expressed on nerve cells, and NMUR1, present on ILC2, their progenitors, and to a much lower degree on $\mathrm{T}$ cells (41, 87). NMU can be induced by $N$. brasiliensis excretory/secretory products (NES), alarmins (IL-33), and toll like receptor ligands (LPS) in a-MyD88-dependent manner (LPS) (87). Pulmonary ILC2 express NMUR1 at steady state and upon IL-25 stimulation. By contrast, NMUR1 was shown to be downregulated upon IL-33 stimulation (41). Interestingly, NMU and IL-25 act synergistically to upregulate IL-5 and IL-13 mRNA and protein levels when given intranasally over several days (41). NMU alone was shown to be more potent to induce IL-5 and IL-13 mRNA in intestinal than in pulmonary ILC2 in short-term ex vivo stimulations (87). NMU signals via ERK1/2 and induces $\mathrm{Ca}^{2+}$ influx followed by calcineurin and NFAT activation (87). NMU is also induced in the lung and gut during $N$. brasiliensis infection and NMUR1 ${ }^{+}$ ILC2 are superior to NMUR1- ILC2 in fighting off $N$. brasiliensis infection (108). Thus, NMU is an important activator of pulmonary $\operatorname{ILC} 2(41,87,108)$.

\section{Vasoactive Intestinal Peptide (VIP)}

The neuropeptide VIP has been initially described as a polypeptide isolated from the small intestine with diverse effects on different systems such as cardiovascular and respiratory systems (109). VIP is expressed by neurons of the central and peripheral nervous system and can be transmitted by VIP receptor type 1 (VPAC1) or VIP receptor type 2 (VPAC2), which are differently regulated dependent on cell type and activity state $(110,111)$. Interestingly, intestinal and pulmonary ILC2 express VPAC1 and VPAC2 and release IL-5 when they are cultured with IL-7 and 
VIP- or VPAC2-specific agonist (71). An important link between afferent neurons, VIP, ILC2, and T cells was reported by Talbot and colleagues (112). IL-5 released by ILC2 stimulates nociceptors on afferent neurons and induces the release of VIP, which signals via VPAC2 and triggers ILC2 and subsequently T cells to induce more IL-5 and thus creating a type 2 inflammatory feed forward loop highly depending on the neuro-immune axis (112).

\section{Mediators Released by ILC2}

Group 2 innate lymphoid cells also actively shape their microenvironment by the release of several different cytokines mainly IL-5 and IL-13 but also IL-9, IL-10, and amphiregulin (Areg). The secretion of these immune mediators can be beneficial but also detrimental for the host and therefore a well-balanced and fine-tuned release by ILC2 cells is needed.

\section{IL-5}

Upon activation, ILC2 are able to secrete IL-5, which is important for eosinophil homeostasis (71) and B cell function (1). Both B-1 and B-2 cells are important and prominent populations in the lungs. The production of IgA upon co-culture of mesenteric ILC2 and splenic B cells has been shown to be IL-5 dependent (1). In addition, induction of proliferation as well as IgA, IgM, IgE, and IgG1 secretion by B-1 and B-2 cells by peripheral (peritoneal cavity, spleen) and pulmonary ILC2 was observed in ex vivo co-cultures (113). Moreover, pulmonary ILC2 trigger especially IgM secretion by B cells in vivo upon NP-Ficoll administration in an IL-5-dependent manner (113). However, how B cells and ILC2 interact within their pulmonary environment in vivo still needs further investigation. Moreover, ICOS ${ }^{+}$ ILC2 play a beneficial role through their secretion of IL-5 in a bleomycin model in the lungs (114). Interestingly, especially the timing of IL-5 secretion appears to be crucial for the beneficial effect in this disease model, (114). However, future experiments will be needed to decipher the cellular and molecular cascade triggered by IL-5 to support tissue restoration and homeostasis.

\section{IL-9}

The expression of the IL-9 receptor by ILC2 has been reported since their detailed description in 2010 (3), and the autocrine role of IL-9 on ILC2 function was deciphered by using IL-9 reporter and subsequently IL-9 fate mapping mice $(115,116)$. IL-9 reporter mice ( $I L 9^{C r e} R 26 R^{e Y F P}$ ) were used to initially investigate the origin of this cytokine in an IL-33-dependent, papain-induced lung inflammation model where IL-9 production was restricted to innate lymphoid cells (defined as lineage negative, CD45 ${ }^{+}$, Thy $1^{+}$ with mixed expression of ST2, CD25, MHCII, and Sca-I). These ILC2-like cells expressed IL-9 only transiently and switched to produce type 2 signature cytokines IL-5 and IL-13. Moreover, IL-33 but not IL-25 induced IL-9 competent ILC. IL-9 production by ILC was induced by IL- 2 provided by adaptive immune cells, highlighting again the close relationship between innate and adaptive lymphoid cells. In additional work, IL-9 fate mapping and IL-9R-deficient mice were investigated during $N$. brasiliensis infection and in the latter, less type 2 signature cytokines and Areg were detected indicating that IL-9 is key for efficient ILC2 cytokine production and effector functions. Moreover,
IL-9-induced upregulation of BCL3 in these cells is important for their survival (116). Thus, IL-9 acts in an autocrine manner and is important for ILC2 biology. Importantly, IL-2 has been reported to act as a cofactor on ILC2 and increases cell survival and proliferation by triggering NF- $\mathrm{KB}$ activation and gene transcription via p65 translocation (117). Roediger and colleagues investigated the model of eosinophillic crystalline pneumonia, which spontaneously occurred in Rag-deficient mice in their animal facility. Since several challenges of Rag-deficient mice by IL-2 increased levels of ILC2 (88), CXCR6 ${ }^{+}$ILC2 were investigated and identified as predominantly located in the perivascular in the lungs. Moreover, IL-2 alone did not affect cytokine expression but survival and proliferation and works synergistically with IL-33 to enhance type 2 cytokine expression. Interestingly, next to $\mathrm{T}$ cells, $\mathrm{Lin}^{-}$ $\mathrm{CD}^{\text {hi }} \mathrm{CD}^{+}$ILC, potentially ILC3, but no myeloid population including dendritic cells and eosinophils were identified as IL-2 producers in the lungs (117). IL-2 and IL-9 are closely interlinked in directing ILC2 biology and enhanced IL-9 expression is linked to an asthma-like phenotype in mice and humans underscoring the importance of these cytokines (118-121).

\section{IL-10}

The recently described population of regulatory ILC are able to produce IL-10 (122); however, IL-10 production by ILC2 has already been reported (2). Recently, IL-10-producing ILC2 have been observed upon IL-33 or papain challenge in IL-10 reporter mice (123). Interestingly, IL-10 production of ILC2 is transient and decreases after weeks. Although these IL-10-producing ILC2 have a unique profile, they keep ST2 receptor upregulated and do not express T-bet (123).

\section{IL-13}

With the release of IL-13, ILC2 target non-immune and immune cells in the lungs. Through IL-13 release, ILC2 can initiate mucus secretion but also goblet cell hyperplasia. Whereas controlled mucus secretion is needed to repel particles from the lungs, overproduction of IL-13 leads to goblet cell hyperplasia overexpression of mucus and can thereby also negatively affect tight junctions in the lungs (124). However, the exact pattern of IL-13 receptors on cells of pulmonary origin at steady state and during immune challenge is not yet fully understood. Moreover, IL-13 can induce smooth muscle contraction (125). In addition, ILC2 can prime alveolar macrophages during ontogeny by release of IL-13 into a type 2 immune cell phenotype (126). In addition, ILC2 can target dendritic cells and propagate their migration from the lungs to the LNs in an IL-13-dependent manner (127). Thus, ILC2 are able to influence and trigger innate and adaptive pulmonary type 2 immune responses through release of IL-13.

\section{Amphiregulin (Areg)}

Group 2 innate lymphoid cells contribute to pulmonary wound healing upon influenza infection via the secretion of Areg (14), which belongs to the family of epidermal growth factors (EGF) and signals via the EGF receptor (EGFR) (128). Although the detailed expression pattern of EGFR on pulmonary cells is not yet completely elucidated, EGFR has been reported to be expressed by non-hematopoietic and by hematopoietic cells (129). Whereas 
wound healing and the initiation of mucus secretion is beneficial in some respiratory diseases, it may also be a disadvantage in diseases with enhanced, adverse, and overproduction of mucus (52). Moreover, enhanced EGFR stimulation or signaling has also been implicated to be detrimental in asthma (130). In addition to ILC2, pulmonary Tregs are also able to secrete Areg upon influenza virus infection independent of TCR signaling (131). As such, innate Areg expression by Tregs and ILC2 constitutes an important mechanism to promote wound healing and tissue homeostasis after pulmonary challenge.

\section{LUNG ILC2 EXERT IMPORTANT EFFECTOR FUNCTIONS IN PULMONARY DISEASES}

\section{Respiratory Virus Infections}

Lung infections are the most prevalent infections independent of the economic status of a country and thereby represent a significant disease burden (132). Respiratory virus infections have a high infection and mortality rate worldwide with influenza virus infections alone accounting for approximately 250,000 deaths each year (133). Infections with respiratory viruses can affect the upper [rhinovirus and respiratory syncytial virus (RSV)] as well as the lower respiratory tract [(para-)influenza virus] and often occur in combination with asthma and asthma exacerbations (134). Mice are often used to study respiratory virus infections and the virus is in general administered intranasally to anesthetized mice. Importantly, ILC2 have been shown to be induced upon respiratory virus infections in mice and humans $(7,12,14$, 135-138) and induce an asthma-like phenotype in mice even in the absence of adaptive immunity (7).

\section{Influenza A Virus (IAV)}

Influenza A virus infection has been shown to induce IL-33 and thereby elicit ILC2 $(7,14,135)$. In an infection model using IAV (H3N1 strain), it was shown that ILC2 drive airway hyper-responsiveness (AHR) independently of the adaptive immune response. In this model, alveolar macrophages have been reported to be an important source of IL-33, while eosinophils have not been induced early in infection (7). Another report by Monticelli et al. observed an increase of ILC2 in combination with eosinophilia and identified the contribution of ILC2-derived Areg in wound healing upon infection with a mouse-adapted recombinant H1N1 IAV strain (14). We have recently shown that H1N1-PR8 IAV strain induced eosinophilia as well as neutrophil recruitment and pulmonary type 2 immunopathology. Furthermore, we observed that this immunopathology is significantly increased in interferon receptor 1-deficient animals and identified type I interferon as an important negative regulator to restrain ILC2 upon pulmonary viral infection (135).

\section{Rhinovirus}

Rhinovirus (RV-16) induces IL-25 mRNA and protein levels in asthmatic patients when compared with healthy individuals (137). The induction of a population of non-T non-NK cells with ST2 and ICOS expression was further reported, which probably corresponds to ILC2 (137). Moreover, rhinovirus (RV-16) infection has been shown to induce IL-33 in asthmatic patients together with a type 2 immune signature in vivo. In addition, human Th2 and ILC2 cells can be triggered to secrete type 2 cytokines upon ex vivo stimulation with infected bronchial epithelial cells (138). Moreover, rhinovirus (RV1B, propagated in HeLa cells) can induce IL-25, IL-33, and TSLP protein expression and release, thereby triggering ILC2 expansion and activation in young mice $(136,139)$. Exogenous IFN- $\gamma$ decreases goblet cell hyperplasia, mucus production, and type 2 signature cytokine expression in the lungs through restraint of pulmonary ILC2 in immature mice (140). Thus, elicitation of ILC2 may depend on a combined induction of IL-25, IL-33, and TSLP in both mouse and humans upon rhinovirus infection.

\section{Respiratory Syncytial Virus}

Respiratory syncytial virus infections are often linked to asthma exacerbations especially in children. Increased numbers of ILC2 are highly dependent on IL-33 in young mice upon RSV infection (strain A2, propagated in Vero cells) (141). In adult mice as well, ILC2 are elicited upon RSV infection (strain 01/2-20, human isolate, propagated in Hep-2 cells) and the main source of IL-13 early in the infection leading to AHR, goblet cell hyperplasia, and increased mucus production (142). Furthermore, TSLP, probably released by epithelial cells, has been shown to be important for ILC2 activation in this model (142). Interestingly, RSV is able to trigger ILC2 and ILC3 accumulation in the lungs in STAT1deficient animals resulting in a mixed type 1 and type 2 immune response (143), a phenotype, which is observed sometimes in human asthma (144).

\section{Helminth Infections}

Helminth infections are the most common infections worldwide with approximately 1.5 billion people affected, which equals approximately one-fourth of the world's population (145). Most helminth infections are not life-threatening for humans, but represent a massive health and economic burden. Type 2 immune responses are essential to efficiently expel the worm and protect from re-infections and ILC2 were shown to participate in and amplify these immune responses.

\section{Nippostrongylus brasiliensis}

Nippostrongylus brasiliensis, a natural rodent helminth, is often used as a model of helminth infections. Upon subcutaneous injection of mice with worm larvae (L3), the larvae migrate into the lungs, molt, get coughed up, swallowed and then reach the intestine (146). ILC2 were initially identified in studies using $N$. brasiliensis as a helminth infection model (1-3). Early on during the infection, ILC2 are induced and responsible for the induction of type 2 signature cytokines, especially IL-13 (1-3). IL-13 release by ILC2 is essential for clearance of the infection since lack of IL-13 results in inefficient worm expulsion and transfer of wild-type ILC2 into IL-13-deficient mice can restore worm clearance (2). In addition, eosinophil counts significantly increase in the lungs upon $N$. brasiliensis infection $(2,3,147)$. At the early stage of infection, the lung tissue is extremely fragile, as demonstrated by the increase of red blood cells in 
the bronchiolar alveolar lavage $(147,148)$. Using reporter mice, pulmonary ILC2 were identified as the early source for IL-13 and IL-9 during $N$. brasiliensis infection $(3,71,116)$. As IL-9 is an important autocrine cytokine that regulates fitness of ILC2, ILC2 and eosinophil levels were found to be reduced in IL-9 receptor-deficient mice (116) (see also paragraph about IL-9). Moreover, the recently identified nILC2 and iILC2 in the lungs are both induced upon $N$. brasiliensis infection albeit with different kinetics: iILC2 are induced early on and nILC2 are dominant in the lungs at late timepoints post infection, suggesting that iILC2 may act as transient progenitors of nILC2 in this setting (43).

\section{Bacterial Infections}

Bacterial infections and their link to ILC2 have not yet been addressed in many settings. Two models of bacterial infections, Haemophilus influenzae and Staphylococcus aureus have been reported to induce a decrease in GATA3 expression in pulmonary ILC2 similar to what has been reported in influenza infection (85). However, role(s) of pulmonary ILC2 in bacterial infections and associated immunopathologies still need to be further elucidated.

\section{Allergen-Driven Disease Models}

Since the description that ILC2 are able to rapidly secrete large amounts of type 2 signatures cytokines upon activation, their role in pulmonary allergic reactions and asthma models has been studied extensively.

\section{House Dust Mite}

Allergic reactions to HDM are a very common clinic manifestation in allergic patients (149). HDM can also induce allergic reactions in mice when administered intranasally and is therefore used as a model system to study cellular and molecular mechanism of allergic asthma (AA) (150). HDM extract is a mixture of different components including Der p1 (endopeptidase $1 /$ mite) and Der p2 (TLR4 agonist) as well as serine and cysteine proteases, exo- and endochitinases and endotoxin (LPS) (151). Collectively, these mixtures have been shown to induce both innate and adaptive immune responses including ILC2, Th1, Th2, and Th17 in combination with eosinophils and neutrophils $(152,153)$. Dose, kinetics and number of administrations as well as the route of administration were shown to influence the outcome of the pulmonary immune response $(152,153)$. However, ILC2 and T cells follow similar kinetics upon HDM administration and T cells are required for complete ILC2 function in this model (153).

\section{Papain Model}

Papain is a cysteine protease present in papaya (and other fruit such as pineapple) and has been used in food and drug industries as meat tenderizer but also as tooth whitener in toothpaste and mints. Upon long-term exposure to papain dust, workers in these industries have been reported to develop papain induced asthma in combination with papain specific IgE antibody responses (154). Papain is able to induce an IL-33- and TSLP-dependent type 2 immune response including eosinophilia independent of adaptive immunity in mice $(66,155)$. Early upon intranasal papain administration, pulmonary ILC2 are the dominant source of
IL-5 and IL-13 (66). Dependent on the amount of papain and the number of administrations, increasing levels of NKT and T cells can be detected in the lungs but these seem to be independent of the fitness of pulmonary ILC2 (156). If early (day 0 and 1) and late (day 13 and 20) administration of papain is combined, the support for dendritic cell-dependent priming of Th2 cells by ILC2-derived IL-13 has been reported (127). Thus, papain is an important model to study IL-33-dependent ILC2 function in the pulmonary environment (66).

\section{Cytokine Administration Models to Study ILC2 Biology}

Cytokine administration models (IL-33 or IL-25) are commonly used to study ILC2 biology as they mimic acute type 2 immune responses. These models are less physiological than allergendependent or infection models but their advantage is that they use the controlled activity of specific cytokines or cytokine combinations. Interestingly, IL-33 has been reported to be a more potent trigger of type 2 immune responses than IL- 25 upon intranasal administration (42). However, intranasal administration of NMU in combination with IL-25 was shown to greatly enhance type 2 immune responses (41).

\section{HUMAN ILC2 AND ASTHMA}

As soon as adverse effects of ILC2 were reported in mouse models of pulmonary disease, the concept emerged of establishing ILC2 prevalence in peripheral blood as a biomarker for diagnostic purposes in lung diseases. Increased levels of IL-33 and ILC2 numbers ( $\mathrm{Lin}^{-} \mathrm{IL}-7 \mathrm{Ra}^{+} \mathrm{FceRI}{ }^{-} \mathrm{IL}-33 \mathrm{R}^{+}$) could be detected in bronchioalveolar lavage of asthma patients when compared with disease controls (patients with a disease history) (157). A different study analyzed ILC2 prevalence (gated as $\mathrm{Lin}^{-} \mathrm{CD} 127^{+} \mathrm{CRTH} 2^{+}$or $\left.\mathrm{Lin}^{-} \mathrm{CD} 127^{+} \mathrm{CD} 44^{\text {high }}\right)$ in the peripheral blood of allergic asthma (AA) and allergic rhinitis (AR) patients compared to those of healthy donors (158). In general, ILC2 sorted from PBMCs released large amounts of IL-5 and IL-13 when stimulated with IL-2 and IL-33 but only negligible amounts of IL-4. Type 2 cytokine release of PBMCs from AA was increased compared with AR patients upon stimulation. However, PBMCs from healthy donors also secreted a robust level of type 2 signature cytokines but ILC2 prevalence per $\mathrm{mL}$ blood was slightly increased in AA patients compared with allergic and healthy donors. Another study compared ILC2 levels (gated on $\mathrm{Lin}^{-} \mathrm{CD} 45^{+} \mathrm{CD} 127^{+} \mathrm{ST} 2^{+}$) in blood and sputum of severe asthma, steroid-naïve atopic asthma with healthy controls (159). ILC2 levels as well as type 2 signature positive ILC2 were increased in severe asthma compared with mild asthma patients and eosinophilia was positively correlated. Interestingly, highdose corticosteroid did not completely reduce ILC2 numbers and signature cytokines, which might be due to TSLP-induced STAT5 phosphorylation in ILC2 which is non-steroid reversible (160). Another report investigated ILC2 $\left(\mathrm{Lin}^{-} \mathrm{CRTH} 2^{+} \mathrm{CD} 127^{+}\right)$ in eosinophilic and non-eosinophilic asthmatic patients, observing a correlation of high ILC2 levels with eosinophilic asthma (161). Asthma is a chronic, heterogeneous disease characterized by airway inflammation and hyper-responsiveness and is more 
a syndrome than a disease with one specific pattern. Moreover, asthmatic patients have been reported with higher neuropeptide levels, adding once more the neuro-immune axis (162). Thus, ILC2 characterization in different asthmatic subgroups and their comparison is needed and the use of ILC2 levels as a biomarker needs to be carefully evaluated for each subgroup.

\section{COUNTERACTING ILC2 TO AMELIORATE PULMONARY DISEASES}

Group 2 innate lymphoid cells are critical initiators and amplifiers of type 2 immune responses. Therefore, understanding the regulation of ILC2 will help to understand how type 2 immune responses can be regulated in general. Type I and II interferons have been recently shown to be important in restricting ILC2 effector functions $(8,12,135)$. Importantly, also IL-27, a member of the IL-12 cytokine family, is able to suppress ILC2 function $(12,135,163)$. These reports showed that both interferons and IL-27 restrain ILC2 by STAT1 activation and thereby act as negative regulators of ILC2-mediated responses (12, 135). Interestingly, IL-27 can also restrict ILC2 via activation of STAT3 (163). However, STAT1 activation has been recently reported to not only restrain ILC2 but also exhibit negative regulatory potential on ILC3 (143). Interestingly, the IL-10 receptor is expressed on ILC2 from the mesentery, but no inhibitory effect of IL-10 was observed ex vivo $(1,12)$. However, pulmonary ILC2 upon challenge with papain or IL-33 are restrained when cultured ex vivo with IL-10 (164). This is of special interest as the recently described regulatory ILC execute their suppressive anti-inflammatory functions independent of Foxp3 but via the release of IL-10 (122). As such, regulatory ILC might constitute important negative regulators of ILC2. Importantly, negative regulation of ILC2 by IL-10 was shown to be dependent on their stimulation by IL-33 (164), further highlighting the importance of the cytokine milieu for ILC2 function. ILC2 sense and express the respective receptors for IL-33, namely ST2 and IL-1 receptor accessory protein and TSLP, TSLP receptor chain together with the IL-7R $\alpha$ chain (107). IL-33 signal transduction results in MyD88-dependent activation of NF- $\mathrm{KB}$ and MAPK pathways, whereas TSLP mainly signals via STAT5. In human ILC2, TSLP induces cytokine expression by triggering GATA3 expression through STAT5 phosphorylation (17). Polymorphisms in genetic loci of IL-33, its receptor ST2 (IL1RL1), and TSLP have been identified among other genes in genome-wide association studies in asthmatic patients (165) and monoclonal antibodies specific for TSLP have been positively

\section{REFERENCES}

1. Moro K, Yamada T, Tanabe M, Takeuchi T, Ikawa T, Kawamoto H, et al. Innate production of $\mathrm{T}(\mathrm{H}) 2$ cytokines by adipose tissue-associated c-Kit(+)Sca-1(+) lymphoid cells. Nature (2010) 463:540. doi:10.1038/ nature08636

2. Neill DR, Wong SH, Bellosi A, Flynn RJ, Daly M, Langford TK, et al. Nuocytes represent a new innate effector leukocyte that mediates type-2 immunity. Nature (2010) 464:1367. doi:10.1038/nature08900

3. Price AE, Liang HE, Sullivan BM, Reinhardt RL, Eisley CJ, Erle DJ, et al. Systemically dispersed innate IL-13-expressing cells in type $2 \mathrm{imm}$ - evaluated in asthmatic patients $(166,167)$. Thus, this might be a therapeutical strategy to restrain ILC2 by capturing ILC2 eliciting effectors such as TSLP; however, plasticity of ILC2 might hinder this approach.

\section{SUMMARY AND OUTLOOK}

Since their detailed description in 2010, ILC2 have been studied and followed with huge interest and excitement. In this review, we focused on ILC2 biology and function within their pulmonary environment, giving an overview about lung physiology as well as different disease and allergy models in the lungs in which ILC2 are known to play a role. The pulmonary environment is especially fascinating to study ILC2 biology as they are the predominant ILC population within the lung. Thus, ILC2 play an important role in the initiation but also orchestration of the pulmonary immune response. However, we are just beginning to understand their exact cellular and molecular interactions, their dynamics, and especially their ability of surveillance within the pulmonary tissue at steady state and upon challenge. ILC2 have been mainly reported to play a role in deregulated type 2 immune responses. However, the positive impact of type 2 immune responses has also been proposed (168) and the contribution and the role of ILC2 in this regard has only been started to be elucidated.

\section{AUTHOR CONTRIBUTIONS}

All authors listed have made a substantial, direct, and intellectual contribution to the work and approved it for publication.

\section{FUNDING}

Work in the laboratory of JF is supported by an operating grant from the Canadian Institutes of Health Research (CIHR), a discovery grant by the Natural Sciences and Engineering Research Council (NSERC), and a Leaders of Opportunity infrastructure grant from the Canadian Foundation of Innovation (CFI). JF is supported by a CIHR New Investigator Award and by a Junior 1 and 2 Investigator Award by the Fonds de recherche du Québec Santé (FRQS). CD was supported by the Canadian Institutes of Health Research and the German National Academy of Sciences Leopoldina. JF and CD were supported through The American Association of Immunologists Careers in Immunology Fellowship Program.

unity. Proc Natl Acad Sci U S A (2010) 107:11489. doi:10.1073/pnas. 1003988107

4. Vivier E, van de Pavert SA, Cooper MD, Belz GT. The evolution of innate lymphoid cells. Nat Immunol (2016) 17:790. doi:10.1038/ni.3459

5. Fort MM, Cheung J, Yen D, Li J, Zurawski SM, Lo S, et al. IL-25 induces IL-4, IL-5, and IL-13 and Th2-associated pathologies in vivo. Immunity (2001) 15:985. doi:10.1016/S1074-7613(01)00243-6

6. Allakhverdi Z, Comeau MR, Smith DE, Toy D, Endam LM, Desrosiers M, et al. CD34+ hemopoietic progenitor cells are potent effectors of allergic inflammation. J Allergy Clin Immunol (2009) 123:472. doi:10.1016/j.jaci.2008. 10.022 
7. Chang YJ, Kim HY, Albacker LA, Baumgarth N, McKenzie AN, Smith DE, et al. Innate lymphoid cells mediate influenza-induced airway hyperreactivity independently of adaptive immunity. Nat Immunol (2011) 12:631. doi:10.1038/ni.2045

8. Molofsky AB, Van Gool F, Liang HE, Van Dyken SJ, Nussbaum JC, Lee J, et al. Interleukin-33 and interferon-gamma counter-regulate group 2 innate lymphoid cell activation during immune perturbation. Immunity (2015) 43:161. doi:10.1016/j.immuni.2015.05.019

9. Spits H, Artis D, Colonna M, Diefenbach A, Di Santo JP, Eberl G, et al. Innate lymphoid cells - a proposal for uniform nomenclature. Nat Rev Immunol (2013) 13:145. doi:10.1038/nri3365

10. Kabata H, Moro K, Koyasu S, Asano K. Group 2 innate lymphoid cells and asthma. Allergol Int (2015) 64:227. doi:10.1016/j.alit.2015.03.004

11. Gasteiger G, Fan X, Dikiy S, Lee SY, Rudensky AY. Tissue residency of innate lymphoid cells in lymphoid and nonlymphoid organs. Science (2015) 350:981. doi:10.1126/science.aac9593

12. Moro K, Kabata H, Tanabe M, Koga S, Takeno N, Mochizuki M, et al. Interferon and IL-27 antagonize the function of group 2 innate lymphoid cells and type 2 innate immune responses. Nat Immunol (2016) 17:76. doi:10.1038/ ni.3309

13. Ealey KN, Moro K, Koyasu S. Are ILC2s Jekyll and Hyde in airway inflammation? Immunol Rev (2017) 278:207. doi:10.1111/imr.12547

14. Monticelli LA, Sonnenberg GF, Abt MC, Alenghat T, Ziegler CG, Doering TA, et al. Innate lymphoid cells promote lung-tissue homeostasis after infection with influenza virus. Nat Immunol (2011) 12:1045. doi:10.1031/ni.2131

15. Monticelli LA, Buck MD, Flamar AL, Saenz SA, Tait Wojno ED, Yudanin NA, et al. Arginase 1 is an innate lymphoid-cell-intrinsic metabolic checkpoint controlling type 2 inflammation. Nat Immunol (2016) 17:656. doi:10.1038/ ni. 3421

16. Mjösberg JM, Trifari S, Crellin NK, Peters CP, van Drunen CM, Piet B, et al. Human IL-25- and IL-33-responsive type 2 innate lymphoid cells are defined by expression of CRTH2 and CD161. Nat Immunol (2011) 12:1055. doi:10.1038/ni.2104

17. Mjösberg J, Bernink J, Golebski K, Karrich JJ, Peters CP, Blom B, et al. The transcription factor GATA3 is essential for the function of human type 2 innate lymphoid cells. Immunity (2012) 37:649. doi:10.1016/j.immuni.2012. 08.015

18. Whitsett JA, Alenghat T. Respiratory epithelial cells orchestrate pulmonary innate immunity. Nat Immunol (2015) 16:27. doi:10.1038/ni.3045

19. Reid L, Meyrick B, Antony VB, Chang LY, Crapo JD, Reynolds HY. The mysterious pulmonary brush cell: a cell in search of a function. Am J Respir Crit Care Med (2005) 172:136. doi:10.1164/rccm.200502-203WS

20. Wittekindt $\mathrm{OH}$. Tight junctions in pulmonary epithelia during lung inflammation. Pflugers Arch (2017) 469:135. doi:10.1007/s00424-016-1917-3

21. Hallstrand TS, Hackett TL, Altemeier WA, Matute-Bello G, Hansbro PM, Knight DA. Airway epithelial regulation of pulmonary immune homeostasis and inflammation. Clin Immunol (2014) 151:1. doi:10.1016/j.clim.2013. 12.003

22. Rogers DF. Airway goblet cells: responsive and adaptable front-line defenders. Eur Respir J (1994) 7:1690. doi:10.1183/09031936.94.07091678

23. Rock JR, Randell SH, Hogan BL. Airway basal stem cells: a perspective on their roles in epithelial homeostasis and remodeling. Dis Model Mech (2010) 3:545. doi:10.1242/dmm.006031

24. Zhu Z, Homer RJ, Wang Z, Chen Q, Geba GP, Wang J, et al. Pulmonary expression of interleukin-13 causes inflammation, mucus hypersecretion, subepith4elial fibrosis, physiologic abnormalities, and eotaxin production. J Clin Invest (1999) 103:779. doi:10.1172/JCI5909

25. Wills-Karp M, Luyimbazi J, Xu X, Schofield B, Neben TY, Karp CL, et al. Interleukin-13: central mediator of allergic asthma. Science (1998) 282:2258. doi:10.1126/science.282.5397.2258

26. Klose CS, Artis D. Innate lymphoid cells as regulators of immunity, inflammation and tissue homeostasis. Nat Immunol (2016) 17:765. doi:10.1038/ ni. 3489

27. Rawlins EL, Okubo T, Xue Y, Brass DM, Auten RL, Hasegawa H, et al. The role of Scgbla1+ Clara cells in the long-term maintenance and repair of lung airway, but not alveolar, epithelium. Cell Stem Cell (2009) 4:525. doi:10.1016/ j.stem.2009.04.002

28. Chen G, Korfhagen TR, Xu Y, Kitzmiller J, Wert SE, Maeda Y, et al. SPDEF is required for mouse pulmonary goblet cell differentiation and regulates a network of genes associated with mucus production. J Clin Invest (2009) 119:2914. doi:10.1172/JCI39731

29. Boers JE, den Brok JL, Koudstaal J, Arends JW, Thunnissen FB. Number and proliferation of neuroendocrine cells in normal human airway epithelium. Am J Respir Crit Care Med (1996) 154:758. doi:10.1164/ajrccm.154.3.8810616

30. Cutz E. Hyperplasia of pulmonary neuroendocrine cells in infancy and childhood. Semin Diagn Pathol (2015) 32:420. doi:10.1053/j.semdp.2015.08.001

31. Branchfield K, Nantie L, Verheyden JM, Sui P, Wienhold MD, Sun X. Pulmonary neuroendocrine cells function as airway sensors to control lung immune response. Science (2016) 351:707. doi:10.1126/science.aad7969

32. Gu X, Karp PH, Brody SL, Pierce RA, Welsh MJ, Holtzman MJ, et al. Chemosensory functions for pulmonary neuroendocrine cells. Am J Respir Cell Mol Biol (2014) 50:637. doi:10.1165/rcmb.2013-0199OC

33. Cutz E, Yeger H, Pan J. Pulmonary neuroendocrine cell system in pediatric lung disease-recent advances. Pediatr Dev Pathol (2007) 10:419. doi:10.2350/07-04-0267.1

34. Meyrick B, Reid L. The alveolar brush cell in rat lung - a third pneumonocyte. J Ultrastruct Res (1968) 23:71. doi:10.1016/S0022-5320(68)80032-2

35. DiMaio MF, Dische R, Gordon RE, Kattan M. Alveolar brush cells in an infant with desquamative interstitial pneumonitis. Pediatr Pulmonol (1988) 4:185. doi:10.1002/ppul.1950040312

36. Krasteva G, Canning BJ, Hartmann P, Veres TZ, Papadakis T, Mühlfeld C, et al. Cholinergic chemosensory cells in the trachea regulate breathing. Proc Natl Acad Sci U S A (2011) 108:9478. doi:10.1073/pnas.1019418108

37. Saunders CJ, Reynolds SD, Finger TE. Chemosensory brush cells of the trachea. A stable population in a dynamic epithelium. Am J Respir Cell Mol Biol (2013) 49:190. doi:10.1165/rcmb.2012-0485OC

38. von Moltke J, Ji M, Liang HE, Locksley RM. Tuft-cell-derived IL-25 regulates an intestinal ILC2-epithelial response circuit. Nature (2016) 529:221. doi:10.1038/nature16161

39. Gerbe F, Sidot E, Smyth DJ, Ohmoto M, Matsumoto I, Dardalhon V, et al. Intestinal epithelial tuft cells initiate type 2 mucosal immunity to helminth parasites. Nature (2016) 529:226. doi:10.1038/nature16527

40. Howitt MR, Lavoie S, Michaud M, Blum AM, Tran SV, Weinstock JV, et al. Tuft cells, taste-chemosensory cells, orchestrate parasite type 2 immunity in the gut. Science (2016) 351:1329. doi:10.1126/science.aaf1648

41. Wallrapp A, Riesenfeld SJ, Burkett PR, Abdulnour RE, Nyman J, Dionne D, et al. The neuropeptide NMU amplifies ILC2-driven allergic lung inflammation. Nature (2017) 549(7672):351-56. doi:10.1038/nature24029

42. Barlow JL, Peel S, Fox J, Panova V, Hardman CS, Camelo A, et al. IL-33 is more potent than IL-25 in provoking IL-13-producing nuocytes (type 2 innate lymphoid cells) and airway contraction. J Allergy Clin Immunol (2013) 132:933. doi:10.1016/j.jaci.2013.05.012

43. Huang Y, Guo L, Qiu J, Chen X, Hu-Li J, Siebenlist U, et al. IL-25-responsive, lineage-negative KLRG1(hi) cells are multipotential 'inflammatory' type 2 innate lymphoid cells. Nat Immunol (2015) 16:161. doi:10.1038/ni.3078

44. Koyasu S. Inflammatory ILC2 cells: disguising themselves as progenitors? Nat Immunol (2015) 16:133. doi:10.1038/ni.3080

45. Howland RH. Vagus nerve stimulation. Curr Behav Neurosci Rep (2014) 1:64. doi:10.1007/s40473-014-0010-5

46. Chang RB, Strochlic DE, Williams EK, Umans BD, Liberles SD. Vagal sensory neuron subtypes that differentially control breathing. Cell (2015) 161:622. doi:10.1016/j.cell.2015.03.022

47. Undem BJ, Kollarik M. The role of vagal afferent nerves in chronic obstructive pulmonary disease. Proc Am Thorac Soc (2005) 2:355. doi:10.1513/ pats.200504-033SR

48. Irwin RS, Boulet LP, Cloutier MM, Fuller R, Gold PM, Hoffstein V, et al. Managing cough as a defense mechanism and as a symptom. A consensus panel report of the American college of chest physicians. Chest (1998) 114:133S. doi:10.1378/chest.114.2_Supplement.133S

49. Sparrow MP, Weichselbaum M, McCray PB. Development of the innervation and airway smooth muscle in human fetal lung. Am J Respir Cell Mol Biol (1999) 20:550. doi:10.1165/ajrcmb.20.4.3385

50. Deshpande DA, Wang WC, McIlmoyle EL, Robinett KS, Schillinger RM, An SS, et al. Bitter taste receptors on airway smooth muscle bronchodilate by localized calcium signaling and reverse obstruction. Nat Med (2010) 16:1299. doi:10.1038/nm.2237

51. Huber HL, Koessler KK. The pathology of bronchial asthma. Arch Intern Med (1922) 30:689. doi:10.1001/archinte.1922.00110120002001 
52. Crosby LM, Waters CM. Epithelial repair mechanisms in the lung. Am J Physiol Lung Cell Mol Physiol (2010) 298:L715. doi:10.1152/ajplung.00361.2009

53. Kim CF, Jackson EL, Woolfenden AE, Lawrence S, Babar I, Vogel S, et al. Identification of bronchioalveolar stem cells in normal lung and lung cancer. Cell (2005) 121:823. doi:10.1016/j.cell.2005.03.032

54. Zuo W, Zhang T, Wu DZ, Guan SP, Liew AA, Yamamoto Y, et al. p63(+) $\mathrm{Krt5}(+)$ distal airway stem cells are essential for lung regeneration. Nature (2015) 517:616. doi:10.1038/nature13903

55. Vaughan AE, Brumwell AN, Xi Y, Gotts JE, Brownfield DG, Treutlein B, et al. Lineage-negative progenitors mobilize to regenerate lung epithelium after major injury. Nature (2015) 517:621. doi:10.1038/nature14112

56. Barkauskas CE, Cronce MJ, Rackley CR, Bowie EJ, Keene DR, Stripp BR, et al. Type 2 alveolar cells are stem cells in adult lung. JClin Invest (2013) 123:3025. doi:10.1172/JCI68782

57. Wright JR. Pulmonary surfactant: a front line of lung host defense. J Clin Invest (2003) 111:1453. doi:10.1172/JCI200318650

58. McRitchie DI, Isowa N, Edelson JD, Xavier AM, Cai L, Man HY, et al. Production of tumour necrosis factor alpha by primary cultured rat alveolar epithelial cells. Cytokine (2000) 12:644. doi:10.1006/cyto.1999.0656

59. Kohn HN. Zur Histologie des indurirenden fibrinösen pneumonia. Münch Med Woch (1893) 40:42-5.

60. Bastacky J, Goerke J. Pores of Kohn are filled in normal lungs: lowtemperature scanning electron microscopy. J Appl Physiol (1985) (1992) 73:88. doi:10.1152/jappl.1992.73.1.88

61. Peao MN, Aguas AP, de Sa CM, Grande NR. Morphological evidence for migration of particle-laden macrophages through the interalveolar pores of Kohn in the murine lung. Acta Anat (Basel) (1993) 147:227. doi:10.1159/ 000147509

62. Metzger RJ, Klein OD, Martin GR, Krasnow MA. The branching programme of mouse lung development. Nature (2008) 453:745. doi:10.1038/nature07005

63. Mauroy B, Filoche M, Weibel ER, Sapoval B. An optimal bronchial tree may be dangerous. Nature (2004) 427:633. doi:10.1038/nature02287

64. Mercer RR, Russell ML, Roggli VL, Crapo JD. Cell number and distribution in human and rat airways. Am J Respir Cell Mol Biol (1994) 10:613. doi:10.1165/ ajrcmb.10.6.8003339

65. Toskala E, Smiley-Jewell SM, Wong VJ, King D, Plopper CG. Temporal and spatial distribution of ciliogenesis in the tracheobronchial airways of mice. Am J Physiol Lung Cell Mol Physiol (2005) 289:L454. doi:10.1152/ ajplung.00036.2005

66. Halim TY, Krauss RH, Sun AC, Takei F. Lung natural helper cells are a critical source of Th2 cell-type cytokines in protease allergen-induced airway inflammation. Immunity (2012) 36:451. doi:10.1016/j.immuni.2011. 12.020

67. Hoyler T, Klose CS, Souabni A, Turqueti-Neves A, Pfeifer D, Rawlins EL, et al. The transcription factor GATA- 3 controls cell fate and maintenance of type 2 innate lymphoid cells. Immunity (2012) 37:634. doi:10.1016/j. immuni.2012.06.020

68. Van Dyken SJ, Mohapatra A, Nussbaum JC, Molofsky AB, Thornton EE, Ziegler SF, et al. Chitin activates parallel immune modules that direct distinct inflammatory responses via innate lymphoid type 2 and gammadelta $\mathrm{T}$ cells. Immunity (2014) 40:414. doi:10.1016/j.immuni.2014.02.003

69. Monticelli LA, Osborne LC, Noti M, Tran SV, Zaiss DM, Artis D. IL-33 promotes an innate immune pathway of intestinal tissue protection dependent on amphiregulin-EGFR interactions. Proc Natl Acad Sci U S A (2015) 112:10762. doi:10.1073/pnas.1509070112

70. Gury-BenAri M, Thaiss CA, Serafini N, Winter DR, Giladi A, Lara-Astiaso D, et al. The spectrum and regulatory landscape of intestinal innate lymphoid cells are shaped by the microbiome. Cell (2016) 166:1231. doi:10.1016/j. cell.2016.07.043

71. Nussbaum JC, Van Dyken SJ, von Moltke J, Cheng LE, Mohapatra A, Molofsky AB, et al. Type 2 innate lymphoid cells control eosinophil homeostasis. Nature (2013) 502:245. doi:10.1038/nature12526

72. Wojno ED, Monticelli LA, Tran SV, Alenghat T, Osborne LC, Thome JJ, et al. The prostaglandin $\mathrm{D}(2)$ receptor CRTH2 regulates accumulation of group 2 innate lymphoid cells in the inflamed lung. Mucosal Immunol (2015) 8:1313. doi:10.1038/mi.2015.21

73. Steer CA, Martinez-Gonzalez I, Ghaedi M, Allinger P, Mathä L, Takei F. Group 2 innate lymphoid cell activation in the neonatal lung drives type 2 immunity and allergen sensitization. J Allergy Clin Immunol (2017) 140(2):593-5.e3. doi:10.1016/j.jaci.2016.12.984

74. de Kleer IM, Kool M, de Bruijn MJ, Willart M, van Moorleghem J, Schuijs MJ, et al. Perinatal activation of the interleukin-33 pathway promotes type 2 immunity in the developing lung. Immunity (2016) 45:1285. doi:10.1016/j. immuni.2016.10.031

75. Stier MT, Zhang J, Goleniewska K, Cephus JY, Rusznak M, Wu L, et al. IL-33 promotes the egress of group 2 innate lymphoid cells from the bone marrow. J Exp Med (2018) 215:263. doi:10.1084/jem.20170449

76. Yu Y, Tsang JC, Wang C, Clare S, Wang J, Chen X, et al. Single-cell RNA-seq identifies a PD-1hi ILC progenitor and defines its development pathway. Nature (2016) 539:102. doi:10.1038/nature20105

77. Martinez-Gonzalez I, Mathä L, Steer CA, Ghaedi M, Poon GF, Takei F. Allergen-experienced group 2 innate lymphoid cells acquire memory-like properties and enhance allergic lung inflammation. Immunity (2016) 45:198. doi:10.1016/j.immuni.2016.06.017

78. Huang Y, Mao K, Chen X, Sun MA, Kawabe T, Li W, et al. S1P-dependent interorgan trafficking of group 2 innate lymphoid cells supports host defense. Science (2018) 359:114. doi:10.1126/science.aam5809

79. Baeyens A, Fang V, Chen C, Schwab SR. Exit strategies: S1P signaling and T cell migration. Trends Immunol (2015) 36:778. doi:10.1016/j.it.2015. 10.005

80. Huang Y, Mao K, Chen X, Sun MA, Kawabe T, Li W, et al. CCR7-dependent trafficking of RORgamma(+) ILCs creates a unique microenvironment within mucosal draining lymph nodes. Nat Commun (2015) 6:5862. doi:10.1038/ncomms6862

81. Kim MH, Taparowsky EJ, Kim CH. Retinoic acid differentially regulates the migration of innate lymphoid cell subsets to the gut. Immunity (2015) 43:107. doi:10.1016/j.immuni.2015.06.009

82. Mao K, Baptista AP, Tamoutounour S, Zhuang L, Bouladoux N, Martins AJ, et al. Innate and adaptive lymphocytes sequentially shape the gut microbiota and lipid metabolism. Nature (2018) 554:255. doi:10.1038/nature25437

83. Fang V, Chaluvadi VS, Ramos-Perez WD, Mendoza A, Baeyens A, Rivera R, et al. Gradients of the signaling lipid S1P in lymph nodes position natural killer cells and regulate their interferon-gamma response. Nat Immunol (2017) 18:15. doi:10.1038/ni.3619

84. Lombardi V, Beuraud C, Neukirch C, Moussu H, Morizur L, Horiot S, et al. Circulating innate lymphoid cells are differentially regulated in allergic and nonallergic subjects. J Allergy Clin Immunol (2016) 138:305. doi:10.1016/j. jaci.2015.12.1325

85. Silver JS, Kearley J, Copenhaver AM, Sanden C, Mori M, Yu L, et al. Inflammatory triggers associated with exacerbations of COPD orchestrate plasticity of group 2 innate lymphoid cells in the lungs. Nat Immunol (2016) 17:626. doi:10.1038/ni.3443

86. Lechner AJ, Driver IH, Lee J, Conroy CM, Nagle A, Locksley RM, et al. Recruited monocytes and type 2 immunity promote lung regeneration following pneumonectomy. Cell Stem Cell (2017) 21:120. doi:10.1016/j. stem.2017.03.024

87. Cardoso V, Chesné J, Ribeiro H, García-Cassani B, Carvalho T, Bouchery T, et al. Neuronal regulation of type 2 innate lymphoid cells via neuromedin $U$. Nature (2017) 549(7671):277-81. doi:10.1038/nature23469

88. Roediger B, Kyle R, Yip KH, Sumaria N, Guy TV, Kim BS, et al. Cutaneous immunosurveillance and regulation of inflammation by group 2 innate lymphoid cells. Nat Immunol (2013) 14:564. doi:10.1038/ni.2584

89. Ohne Y, Silver JS, Thompson-Snipes L, Collet MA, Blanck JP, Cantarel BL, et al. IL-1 is a critical regulator of group 2 innate lymphoid cell function and plasticity. Nat Immunol (2016) 17:646. doi:10.1038/ni.3447

90. Bal SM, Bernink JH, Nagasawa M, Groot J, Shikhagaie MM, Golebski K, et al. IL-1beta, IL-4 and IL-12 control the fate of group 2 innate lymphoid cells in human airway inflammation in the lungs. Nat Immunol (2016) 17:636. doi:10.1038/ni.3444

91. Yoshinaga SK, Whoriskey JS, Khare SD, Sarmiento U, Guo J, Horan T, et al. T-cell co-stimulation through B7RP-1 and ICOS. Nature (1999) 402:827. doi: $10.1038 / 45582$

92. Leconte J, Bagherzadeh Yazdchi S, Panneton V, Suh WK. Inducible costimulator (ICOS) potentiates TCR-induced calcium flux by augmenting PLCgammal activation and actin remodeling. Mol Immunol (2016) 79:38. doi:10.1016/j.molimm.2016.09.022 
93. Paclik D, Stehle C, Lahmann A, Hutloff A, Romagnani C. ICOS regulates the pool of group 2 innate lymphoid cells under homeostatic and inflammatory conditions in mice. Eur Immunol (2015) 45:2766. doi:10.1002/eji.201545635

94. Maazi H, Patel N, Sankaranarayanan I, Suzuki Y, Rigas D, Soroosh P, et al. ICOS:ICOS-ligand interaction is required for type 2 innate lymphoid cell function, homeostasis, and induction of airway hyperreactivity. Immunity (2015) 42:538. doi:10.1016/j.immuni.2015.02.007

95. Rigas D, Lewis G, Aron JL, Wang B, Banie H, Sankaranarayanan I, et al. Type 2 innate lymphoid cell suppression by regulatory $\mathrm{T}$ cells attenuates airway hyperreactivity and requires inducible T-cell costimulator-inducible T-cell costimulator ligand interaction. J Allergy Clin Immunol (2017) 139:1468. doi:10.1016/j.jaci.2016.08.034

96. Sharpe AH, Pauken KE. The diverse functions of the PD1 inhibitory pathway. Nat Rev Immunol (2017) 18(3):153-67. doi:10.1038/nri.2017.108

97. Taylor S, Huang Y, Mallett G, Stathopoulou C, Felizardo TC, Sun MA, et al. PD-1 regulates KLRG1+ group 2 innate lymphoid cells. J Exp Med (2017) 214:1663. doi:10.1084/jem.20161653

98. Schwartz C, Khan AR, Floudas A, Saunders SP, Hams E, Rodewald HR, et al. ILC2s regulate adaptive Th2 cell functions via PD-L1 checkpoint control. J Exp Med (2017) 214:2507. doi:10.1084/jem.20170051

99. Henson SM, Akbar AN. KLRG1 - more than a marker for T cell senescence. Age (Dordr) (2009) 31:285. doi:10.1007/s11357-009-9100-9

100. Salimi M, Barlow JL, Saunders SP, Xue L, Gutowska-Owsiak D, Wang X, et al. A role for IL-25 and IL-33-driven type- 2 innate lymphoid cells in atopic dermatitis. J Exp Med (2013) 210:2939. doi:10.1084/jem.20130351

101. Hartsock A, Nelson WJ. Adherens and tight junctions: structure, function and connections to the actin cytoskeleton. Biochim Biophys Acta (2008) 1778:660. doi:10.1016/j.bbamem.2007.07.012

102. Masuyama K, Morishima Y, Ishii $Y$, Nomura A, Sakamoto T, Kimura T, et al. Sputum E-cadherin and asthma severity. JAllergy Clin Immunol (2003) 112:208. doi:10.1067/mai.2003.1526

103. Mebius RE, Rennert P, Weissman IL. Developing lymph nodes collect CD4+CD3- LTbeta+ cells that can differentiate to APC, NK cells, and follicular cells but not T or B cells. Immunity (1997) 7:493. doi:10.1016/ S1074-7613(00)80371-4

104. Huntington ND, Vosshenrich CA, Di Santo JP. Developmental pathways that generate natural-killer-cell diversity in mice and humans. Nat Rev Immunol (2007) 7:703. doi:10.1038/nri2154

105. Mirchandani AS, Besnard AG, Yip E, Scott C, Bain CC, Cerovic V, et al. Type 2 innate lymphoid cells drive CD4+ Th2 cell responses. J Immunol (2014) 192:2442. doi:10.4049/jimmunol.1300974

106. Oliphant CJ, Hwang YY, Walker JA, Salimi M, Wong SH, Brewer JM, et al. MHCII-mediated dialog between group 2 innate lymphoid cells and CD4(+) $\mathrm{T}$ cells potentiates type 2 immunity and promotes parasitic helminth expulsion. Immunity (2014) 41:283. doi:10.1016/j.immuni.2014.06.016

107. Duerr CU, Fritz JH. Regulation of group 2 innate lymphoid cells. Cytokine (2016) 87:1-8. doi:10.1016/j.cyto.2016.01.018

108. Klose CSN, Mahlakõiv T, Moeller JB, Rankin LC, Flamar AL, Kabata H, et al. The neuropeptide neuromedin $\mathrm{U}$ stimulates innate lymphoid cells and type 2 inflammation. Nature (2017) 549(7671):282-6. doi:10.1038/nature23676

109. Said SI, Mutt V. Polypeptide with broad biological activity: isolation from small intestine. Science (1970) 169:1217. doi:10.1126/science.169.3951.1217

110. Lara-Marquez M, O’Dorisio M, O’Dorisio T, Shah M, Karacay B. Selective gene expression and activation-dependent regulation of vasoactive intestinal peptide receptor type 1 and type 2 in human T cells. JImmunol (2001) 166:2522. doi:10.4049/jimmunol.166.4.2522

111. Calvo JR, Pozo D, Guerrero JM. Functional and molecular characterization of VIP receptors and signal transduction in human and rodent immune systems. Adv Neuroimmunol (1996) 6:39. doi:10.1016/S0960-5428(96)00005-8

112. Talbot S, Abdulnour RE, Burkett PR, Lee S, Cronin SJ, Pascal MA, et al. Silencing nociceptor neurons reduces allergic airway inflammation. Neuron (2015) 87:341. doi:10.1016/j.neuron.2015.06.007

113. Drake LY, Iijima K, Bartemes K, Kita H. Group 2 innate lymphoid cells promote an early antibody response to a respiratory antigen in mice. J Immunol (2016) 197:1335. doi:10.4049/jimmunol.1502669

114. Hrusch CL, Manns ST, Bryazka D, Casaos J, Bonham CA, Jaffery MR, et al. ICOS protects against mortality from acute lung injury through activation of IL-5+ ILC2s. Mucosal Immunol (2018) 11(1):61-70. doi:10.1038/mi.2017.42
115. Wilhelm C, Hirota K, Stieglitz B, Van Snick J, Tolaini M, Lahl K, et al. An IL-9 fate reporter demonstrates the induction of an innate IL-9 response in lung inflammation. Nat Immunol (2011) 12:1071. doi:10.1038/ni.2133

116. Turner JE, Morrison PJ, Wilhelm C, Wilson M, Ahlfors H, Renauld JC, et al. IL-9-mediated survival of type 2 innate lymphoid cells promotes damage control in helminth-induced lung inflammation. J Exp Med (2013) 210:2951. doi:10.1084/jem.20130071

117. Roediger B, Kyle R, Tay SS, Mitchell AJ, Bolton HA, Guy TV, et al. IL-2 is a critical regulator of group 2 innate lymphoid cell function during pulmonary inflammation. J Allergy Clin Immunol (2015) 136:1653. doi:10.1016/j. jaci.2015.03.043

118. Erpenbeck VJ, Hohlfeld JM, Volkmann B, Hagenberg A, Geldmacher H, Braun A, et al. Segmental allergen challenge in patients with atopic asthma leads to increased IL-9 expression in bronchoalveolar lavage fluid lymphocytes. J Allergy Clin Immunol (2003) 111:1319. doi:10.1067/mai.2003.1485

119. Temann UA, Geba GP, Rankin JA, Flavell RA. Expression of interleukin 9 in the lungs of transgenic mice causes airway inflammation, mast cell hyperplasia, and bronchial hyperresponsiveness. J Exp Med (1998) 188:1307. doi:10.1084/jem.188.7.1307

120. Temann UA, Laouar Y, Eynon EE, Homer R, Flavell RA. IL9 leads to airway inflammation by inducing IL13 expression in airway epithelial cells. Int Immunol (2007) 19:1. doi:10.1093/intimm/dxl117

121. Shimbara A, Christodoulopoulos P, Soussi-Gounni A, Olivenstein R, Nakamura Y, Levitt RC, et al. IL-9 and its receptor in allergic and nonallergic lung disease: increased expression in asthma. J Allergy Clin Immunol (2000) 105:108. doi:10.1016/S0091-6749(00)90185-4

122. Wang S, Xia P, Chen Y, Qu Y, Xiong Z, Ye B, et al. Regulatory innate lymphoid cells control innate intestinal inflammation. Cell (2017) 171:201. doi:10.1016/j.cell.2017.07.027

123. Seehus CR, Kadavallore A, Torre B, Yeckes AR, Wang Y, Tang J, et al. Alternative activation generates IL-10 producing type 2 innate lymphoid cells. Nat Commun (2017) 8:1900. doi:10.1038/s41467-017-02023-Z

124. Sugita K, Steer CA, Martinez-Gonzalez I, Altunbulakli C, Morita H, CastroGiner F, et al. Type 2 innate lymphoid cells disrupt bronchial epithelial barrier integrity by targeting tight junctions through IL-13 in asthmatic patients. J Allergy Clin Immunol (2017). doi:10.1016/j.jaci.2017.02.038

125. Doeing DC, Solway J. Airway smooth muscle in the pathophysiology and treatment of asthma. J Appl Physiol (1985) (2013) 114:834. doi:10.1152/ japplphysiol.00950.2012

126. Saluzzo S, Gorki AD, Rana BMJ, Martins R, Scanlon S, Starkl P, et al. Firstbreath-induced type 2 pathways shape the lung immune environment. Cell Rep (2017) 18:1893. doi:10.1016/j.celrep.2017.01.071

127. Halim TY, Steer CA, Mathä L, Gold MJ, Martinez-Gonzalez I, McNagny KM, et al. Group 2 innate lymphoid cells are critical for the initiation of adaptive T helper 2 cell-mediated allergic lung inflammation. Immunity (2014) 40:425. doi:10.1016/j.immuni.2014.01.011

128. Zaiss DMW, Gause WC, Osborne LC, Artis D. Emerging functions of amphiregulin in orchestrating immunity, inflammation, and tissue repair. Immunity (2015) 42:216. doi:10.1016/j.immuni.2015.01.020

129. Zaiss DM, van Loosdregt J, Gorlani A, Bekker CP, Gröne A, Sibilia M, et al. Amphiregulin enhances regulatory $\mathrm{T}$ cell-suppressive function via the epidermal growth factor receptor. Immunity (2013) 38:275. doi:10.1016/j. immuni.2012.09.023

130. Puddicombe SM, Polosa R, Richter A, Krishna MT, Howarth PH, Holgate ST, et al. Involvement of the epidermal growth factor receptor in epithelial repair in asthma. FASEB J (2000) 14:1362. doi:10.1096/f.14.10.1362

131. Arpaia N, Green JA, Moltedo B, Arvey A, Hemmers S, Yuan S, et al. A distinct function of regulatory T cells in tissue protection. Cell (2015) 162:1078. doi:10.1016/j.cell.2015.08.021

132. Mizgerd JP. Lung infection - a public health priority. PLoS Med (2006) 3:e76. doi:10.1371/journal.pmed.0030076

133. Available from: http://www.who.int/mediacentre/factsheets/fs211/en/ (Accessed: December 2017).

134. Carroll KN, Hartert TV. The impact of respiratory viral infection on wheezing illnesses and asthma exacerbations. Immunol Allergy Clin North Am (2008) 28:539. doi:10.1016/j.iac.2008.03.001

135. Duerr CU, McCarthy CD, Mindt BC, Rubio M, Meli AP, Pothlichet J, et al. Type I interferon restricts type 2 immunopathology through the regulation 
of group 2 innate lymphoid cells. Nat Immunol (2016) 17:65. doi:10.1038/ ni. 3308

136. Hong JY, Bentley JK, Chung Y, Lei J, Steenrod JM, Chen Q, et al. Neonatal rhinovirus induces mucous metaplasia and airways hyperresponsiveness through IL-25 and type 2 innate lymphoid cells. J Allergy Clin Immunol (2014) 134:429. doi:10.1016/j.jaci.2014.04.020

137. Beale J, Jayaraman A, Jackson DJ, Macintyre JDR, Edwards MR, Walton RP, et al. Rhinovirus-induced IL-25 in asthma exacerbation drives type $2 \mathrm{immu}-$ nity and allergic pulmonary inflammation. Sci Transl Med (2014) 6:256ra134. doi:10.1126/scitranslmed.3009124

138. Jackson DJ, Makrinioti H, Rana BM, Shamji BW, Trujillo-Torralbo MB, Footitt J, et al. IL-33-dependent type 2 inflammation during rhinovirusinduced asthma exacerbations in vivo. Am J Respir Crit Care Med (2014) 190:1373. doi:10.1164/rccm.201406-1039OC

139. Han M, Rajput C, Hong JY, Lei J, Hinde JL, Wu Q, et al. The innate cytokines IL-25, IL-33, and TSLP cooperate in the induction of type 2 innate lymphoid cell expansion and mucous metaplasia in rhinovirus-infected immature mice. J Immunol (2017) 199:1308. doi:10.4049/jimmunol.1700216

140. Han M, Hong JY, Jaipalli S, Rajput C, Lei J, Hinde JL, et al. IFN-gamma blocks development of an asthma pheno-type in rhinovirus-infected baby mice by inhibiting type 2 innate lymphoid cells. Am J Respir Cell Mol Biol (2017) 56:242. doi:10.1165/rcmb.2016-0056OC

141. Saravia J, You D, Shrestha B, Jaligama S, Siefker D, Lee GI, et al. Respiratory syncytial virus disease is mediated by age-variable IL-33. PLoS Pathog (2015) 11:e1005217. doi:10.1371/journal.ppat.1005217

142. Stier MT, Bloodworth MH, Toki S, Newcomb DC, Goleniewska K, Boyd KL, et al. Respiratory syncytial virus infection activates IL-13-producing group 2 innate lymphoid cells through thymic stromal lymphopoietin. J Allergy Clin Immunol (2016) 138:814. doi:10.1016/j.jaci.2016.01.050

143. Stier MT, Goleniewska K, Cephus JY, Newcomb DC, Sherrill TP, Boyd KL, et al. STAT1 represses cytokine-producing group 2 and group 3 innate lymphoid cells during viral infection. J Immunol (2017) 199:510. doi:10.4049/ jimmunol.1601984

144. Bhakta NR, Woodruff PG. Human asthma phenotypes: from the clinic, to cytokines, and back again. Immunol Rev (2011) 242:220. doi:10.1111/ j.1600-065X.2011.01032.x

145. Available from: http://www.who.int/mediacentre/factsheets/fs366/en/ (Accessed: December 2017).

146. Camberis M, Le Gros G, Urban J Jr. Animal model of Nippostrongylus brasiliensis and Heligmosomoides polygyrus. Curr Protoc Immunol (2003) Chapter 19:Unit 19.12. doi:10.1002/0471142735.im1912s55

147. Hung LY, Lewkowich IP, Dawson LA, Downey J, Yang Y, Smith DE, et al. IL-33 drives biphasic IL-13 production for noncanonical Type 2 immunity against hookworms. Proc Natl Acad Sci U S A (2013) 110:282. doi:10.1073/ pnas. 1206587110

148. Chen F, Liu Z, Wu W, Rozo C, Bowdridge S, Millman A, et al. An essential role for TH2-type responses in limiting acute tissue damage during experimental helminth infection. Nat Med (2012) 18:260. doi:10.1038/nm.2628

149. Blomme K, Tomassen P, Lapeere H, Huvenne W, Bonny M, Acke F, et al. Prevalence of allergic sensitization versus allergic rhinitis symptoms in an unselected population. Int Arch Allergy Immunol (2013) 160:200. doi:10.1159/ 000339853

150. Gregory LG, Lloyd CM. Orchestrating house dust mite-associated allergy in the lung. Trends Immunol (2011) 32:402. doi:10.1016/j.it.2011.06.006

151. Post S, Nawijn MC, Hackett TL, Baranowska M, Gras R, van Oosterhout AJ, et al. The composition of house dust mite is critical for mucosal barrier dysfunction and allergic sensitisation. Thorax (2012) 67:488. doi:10.1136/ thoraxjnl-2011-200606

152. Haspeslagh E, Debeuf N, Hammad H, Lambrecht BN. Murine models of allergic asthma. Methods Mol Biol (2017) 1559:121. doi:10.1007/ 978-1-4939-6786-5_10

153. Li BW, de Bruijn MJ, Tindemans I, Lukkes M, KleinJan A, Hoogsteden HC, et al. T cells are necessary for ILC2 activation in house dust mite-induced allergic airway inflammation in mice. Eur J Immunol (2016) 46:1392. doi:10.1002/eji.201546119

154. Novey HS, Marchioli LE, Sokol WN, Wells ID. Papain-induced asthma physiological and immunological features. JAllergy Clin Immunol (1979) 63:98. doi:10.1016/0091-6749(79)90198-2

155. Oboki K, Ohno T, Kajiwara N, Arae K, Morita H, Ishii A, et al. IL-33 is a crucial amplifier of innate rather than acquired immunity. Proc Natl Acad Sci U S A (2010) 107:18581. doi:10.1073/pnas.1003059107

156. Yu X, Pappu R, Ramirez-Carrozzi V, Ota N, Caplazi P, Zhang J, et al. TNF superfamily member TL1A elicits type 2 innate lymphoid cells at mucosal barriers. Mucosal Immunol (2013) 7(3):730-40. doi:10.1038/mi.2013.92

157. Christianson CA, Goplen NP, Zafar I, Irvin C, Good JT Jr, Rollins DR, et al. Persistence of asthma requires multiple feedback circuits involving type 2 innate lymphoid cells and IL-33. J Allergy Clin Immunol (2015) 136:59. doi:10.1016/j.jaci.2014.11.037

158. Bartemes KR, Kephart GM, Fox SJ, Kita H. Enhanced innate type 2 immune response in peripheral blood from patients with asthma. JAllergy Clin Immunol (2014) 134:671. doi:10.1016/j.jaci.2014.06.024

159. Smith SG, Chen R, Kjarsgaard M, Huang C, Oliveria JP, O’Byrne PM, et al. Increased numbers of activated group 2 innate lymphoid cells in the airways of patients with severe asthma and persistent airway eosinophilia. J Allergy Clin Immunol (2016) 137:75. doi:10.1016/j.jaci.2015.05.037

160. Kabata H, Moro K, Fukunaga K, Suzuki Y, Miyata J, Masaki K, et al. Thymic stromal lymphopoietin induces corticosteroid resistance in natural helper cells during airway inflammation. Nat Commun (2013) 4:2675. doi:10.1038/ ncomms 3675

161. Liu T, Wu J, Zhao J, Wang J, Zhang Y, Liu L, et al. Type 2 innate lymphoid cells: a novel biomarker of eosinophilic airway inflammation in patients with mild to moderate asthma. Respir Med (2015) 109:1391. doi:10.1016/j. rmed.2015.09.016

162. Lilly CM, Bai TR, Shore SA, Hall AE, Drazen JM. Neuropeptide content of lungs from asthmatic and nonasthmatic patients. Am J Respir Crit Care Med (1995) 151:548. doi:10.1164/ajrccm.151.2.7531100

163. Mchedlidze T, Kindermann M, Neves AT, Voehringer D, Neurath MF, Wirtz S. IL-27 suppresses type 2 immune responses in vivo via direct effects on group 2 innate lymphoid cells. Mucosal Immunol (2016) 9:1384. doi:10.1038/mi.2016.20

164. Morita H, Arae K, Unno H, Miyauchi K, Toyama S, Nambu A, et al. An Interleukin-33-mast cell-interleukin-2 axis suppresses papain-induced allergic inflammation by promoting regulatory $\mathrm{T}$ cell numbers. Immunity (2015) 43:175. doi:10.1016/j.immuni.2015.06.021

165. Moffatt MF, Gut IG, Demenais F, Strachan DP, Bouzigon E, Heath S, et al. A large-scale, consortium-based genomewide association study of asthma. N Engl J Med (2010) 363:1211. doi:10.1056/NEJMoa0906312

166. Corren J, Parnes JR, Wang L, Mo M, Roseti SL, Griffiths JM, et al. Tezepelumab in adults with uncontrolled asthma. N Engl J Med (2017) 377:936. doi:10.1056/NEJMoa1704064

167. Gauvreau GM, O’Byrne PM, Boulet LP, Wang Y, Cockcroft D, Bigler J, et al. Effects of an anti-TSLP antibody on allergen-induced asthmatic responses. N Engl J Med (2014) 370:2102. doi:10.1056/NEJMoa1402895

168. Palm NW, Rosenstein RK, Medzhitov R. Allergic host defences. Nature (2012) 484:465. doi:10.1038/nature11047

Conflict of Interest Statement: The authors declare that the research was conducted in the absence of any commercial or financial relationships that could be construed as a potential conflict of interest.

Copyright $\odot 2018$ Mindt, Fritz and Duerr. This is an open-access article distributed under the terms of the Creative Commons Attribution License (CC BY). The use, distribution or reproduction in other forums is permitted, provided the original author(s) and the copyright owner are credited and that the original publication in this journal is cited, in accordance with accepted academic practice. No use, distribution or reproduction is permitted which does not comply with these terms. 